Max-Planck-Institut für demografische Forschung

Max Planck Institute for Demographic Research

Konrad-Zuse-Strasse 1 - D-18057 Rostock = Germany = Tel +49 (0) 3812081 - 0 - Fax +49 (0) 3812081 - 202 - www.demogr.mpg.de

MPIDR Working Paper WP 2020-011 I March 2020

https://doi.org/10.4054/MPIDR-WP-2020-011

Does retirement affect secondary preventive care use?

Evidence from breast cancer screening

Peter Eibich I eibich@demogr.mpg.de

Léontine Goldzahl । leontine.goldzahl@edhec.edu

This working paper has been approved for release by: Mathias Lerch (lerch@demogr.mpg.de),

Deputy Head of the Laboratory of Fertility and Well-Being.

(ㄷ) Copyright is held by the authors.

Working papers of the Max Planck Institute for Demographic Research receive only limited review. Views or opinions expressed in working papers are attributable to the authors and do not necessarily reflect those of the Institute. 


\title{
Does retirement affect secondary preventive care use? \\ Evidence from breast cancer screening
}

\author{
Peter Eibich $^{1}$ and Léontine Goldzahl ${ }^{2}$
}

\begin{abstract}
Population ageing is expected to increase the burden of non-communicable diseases, e.g., cardiovascular diseases and cancer. These diseases are amenable to prevention, such as lifestyle changes (primary prevention) and early detection (secondary prevention), and thus prevention is considered to be one of the keys to maintaining the health of an ageing population. This paper examines the causal impact of retirement on secondary preventive care use. While we focus on breast cancer screening, we also provide evidence for other types of screening such as cervical cancer screening. We use five waves of data from the Eurobarometer surveys conducted between 1996 and 2006, covering 25 different European countries. We address the endogeneity of retirement by using age thresholds for pension eligibility as instrumental variables. We find that retirement reduces secondary preventive care use. This effect is not driven by changes in health or income. Instead, our evidence suggests that generosity of the social health insurance system and women's beliefs concerning cancer prevention and treatment are important mechanisms.
\end{abstract}

JEL codes: I12, I18, J26, C26

Keywords: Europe; retirement; health behavior; instrumental variables; preventive care; breast cancer

\footnotetext{
${ }^{1}$ Corresponding author: Max Planck Institute for Demographic Research, Konrad-Zuse-Str. 1, 18057 Rostock, Germany, and Health Economics Research Centre, Nuffield Department of Population Health, University of Oxford, Old Road Campus, Headington, OX3 7LF Oxford, UK. E-Mail: eibich@ demogr.mpg.de. Tel.: +49 (0)381 2081-220.

${ }^{2}$ EDHEC Business School, 24 avenue Gustave Delory, CS 50411, 59057 Roubaix Cedex 1 - France. E-mail: leontine.goldzahl@edhec.edu.
} 
Acknowledgements: We would like to thank Thomas Allen, Clémentine Garrouste, Alastair Gray, Melissa McInerney, Mikko Myrskylä, Ansgar Wübker and Nicolas Ziebarth for their helpful comments and discussion.

Funding and Declaration of Interests: Peter Eibich acknowledges generous support by the Wellcome Trust (Society \& Ethics Research Fellowship 203208/Z/16/Z). The funder was not involved in any aspects of the study. The authors declare no other competing interests.

Data Accessibility: The Eurobarometer data used in this study can be accessed freely via the GESIS Data Service. For further information, please see https://www.gesis.org/eurobarometer-data-service/search-data-access/data-access. 


\section{Introduction}

Population ageing is resulting in an increasing burden of non-communicable diseases for which age is a major risk factor, such as cardiovascular diseases, cancer or type 2 diabetes. For instance, the incidence of cancer in those over 65 is 10 times greater than in those younger than 65 and the cancer death rate is 16 times greater in patients over 65 compared to younger people during the early 2000s (Berger et al., 2006).

Many of these diseases are amenable to prevention. Changes in health behavior such as exercise or quitting smoking (i.e., primary prevention) can reduce the incidence of these diseases, while early detection (i.e., secondary prevention) can improve treatment outcomes and result in higher survival and fewer complications. Thus, preventive care could play a major role in maintaining the health of an ageing population.

Retirement is a major transition for this ageing population, and a growing part of the economic literature has examined the health effects of retirement (see (2017) for an overview). A lot of attention has been devoted to the effect of retirement on primary prevention such as exercise (Celidoni and Rebba, 2017; Eibich, 2015; Insler, 2014; Kämpfen and Maurer, 2016; Motegi et al., 2016; Zantinge et al., 2014). Two other studies analyzed the effect of retirement on secondary prevention. Both Coe and Zamarro (2015) and Frimmel and Pruckner (2018) examine the effect of retirement on healthcare utilization and include screening participation as outcomes. Frimmel and Pruckner (2018) use Austrian register data and find a decrease in participation in health check-ups and prostate-specific antigen testing for men, but no changes in gynecological screening and mammography use for women. Coe and Zamarro (2015) examine cholesterol checks and prostate cancer screening using HRS data. They report no significant changes. ${ }^{3}$ Yet, the mechanisms behind these changes remain unclear. Frimmel and Pruckner (2018) examine heterogeneity by occupation and find that

\footnotetext{
${ }^{3}$ They report a significant increase for flu shots, i.e., primary prevention.
} 
their results (for the screening outcomes) are primarily driven by blue-collar workers. Coe and Zamarro (2015) consider heterogeneity between health systems using SHARE data, and thus do not report estimates for their screening outcomes.

This paper extends the literature by examining the effect of retirement on secondary preventive care with a particular focus on breast cancer screening participation, since breast cancer is the most common cancer among women aged 50 and above. In this paper, we draw on five waves of repeated cross-section data from the Eurobarometer surveys collected between 1996 to 2006 and covering 25 EU countries. We use variation in state pension ages across countries as well as variation within countries over time to identify the causal effect of retirement. Our results suggest that retirement reduces secondary preventive care use for all secondary prevention examined, with the exception of osteoporosis tests. Then, we examine whether the effect of retirement on breast cancer screening participation differs between countries with and without national organized screening programs. We find that screening programs can mitigate the negative effect of retirement to a limited extent. We also systematically investigate potential mechanisms, including some mechanisms that have not been considered previously, such as perceptions on breast cancer prevention and treatment as well as social health insurance (SHI) coverage.

Our study makes contributions along several dimensions. First of all, this is one of the first studies to provide comprehensive evidence of the effect of retirement on secondary preventive care among women and especially on breast cancer screening. While Frimmel and Pruckner (2018) also considered mammography use in a single country, we also provide detailed evidence on other types of secondary prevention for women across 25 different countries .Second, we add to the existing literature by investigating new mechanisms - health insurance coverage and changes in knowledge of breast cancer screening and treatment at retirement. Third, the cross country nature of our data, and the gradual implementation of screening 
programs in Europe allows us to study effect heterogeneity by institutional settings such as the existence of a screening program. Lastly, we assess our results using specification curves, which is a methodological innovation in this strand of the literature.

The next section reviews the theoretical background and the existing empirical literature. Section 3 presents the context and the data, while section 4 describes the methods. Section 5 presents our results and the mechanisms through which retirement affect mammography utilization are depicted in section 6. The final section discusses the results and concludes.

\section{Theoretical considerations and relevant empirical literature}

Previous empirical studies have primarily considered time constraints as the main mechanism linking retirement to changes in primary prevention. Theoretical considerations suggest that income, health, health insurance coverage as well as knowledge on prevention could also explain the relationship between retirement and secondary preventive care use.

Retirement typically leads to a reduction in income. Healthcare might therefore be less accessible after retirement if retirees have less income to pay for co-payments, out-of-pocket expenditures or transportation costs. Galama et al. (2013) suggest another interesting theoretical mechanism based on Grossman's health capital model (Grossman, 1972). Their model predicts that healthcare consumption should decrease after retirement. Post-retirement income is independent of health. While health still has a direct effect on utility, it ceases to affect utility indirectly through consumption, and therefore retirees are expected to reallocate resources from health investments into higher consumption. According to both of these income-driven mechanisms, retirement may lead to a decrease in mammography use. There is a large literature investigating the health effects of retirement, with studies reporting both positive effects (Blake and Garrouste, 2013; Bloemen et al., 2017; Celidoni and Rebba, 2017; Coe and Zamarro, 2011; De Grip et al., 2011; Eibich, 2015; Grøtting and Lillebø, 2017; 
Hallberg et al., 2015; Insler, 2014; Nishimura et al., 2017) and negative effects. ${ }^{4}$ At the same time, several studies find that health is correlated with participation in breast cancer screening (Bouckaert and Schokkaert, 2016; Carrieri and Wuebker, 2016; Courtney-Long et al., 2011; Gandhi et al., 2015; Guilcher et al., 2014; Jensen et al., 2015; Wu, 2003). Taken together, these findings suggest that retirement could affect mammography use through its effect on health but the sign is ambiguous.

Retirement might lead to or coincide with changes in health insurance coverage. For example, in the US, individuals become eligible for Medicare coverage at 65. In contrast, European countries typically have a social health insurance system covering both workers and retirees. However, employees might benefit from employer-sponsored complementary health insurance, workplace-based prevention programs or incentives to participate in existing prevention programs. Retirement might reduce the likelihood to use secondary preventive care if retirees are not covered by such schemes.

Transitions out of the labor force at older ages may induce changes in individual's social networks in terms of both size and composition of the network. Evidence from the US shows that retirement reduces the size and density of social networks (Patacchini and Engelhardt, 2016). Evidence from Europe is mixed. Fletcher (2014) finds that retirement had little impact on social network size while Börsch-Supan and Schuth's (2013) results show that retirement negatively impacts cognitive health through a reduction of the social network. Social networks can influence individuals' behavior by circulating information and beliefs on the effectiveness of recommended health behavior (Berkman and Glass, 2000). Beliefs and knowledge about breast cancer screening have been shown to be key determinants of

\footnotetext{
${ }^{4}$ The survey by Nishimura et al. (2017) suggests that the difference in findings can be attributed to methodological differences, and that a unified approach based on state pension ages provides mostly positive or insignificant results. However, there remains considerable heterogeneity, e.g., across countries. In addition, while all studies focusing on cognitive functioning find negative effects of retirement (Bingley and Martinello, 2013; Bonsang et al., 2012; Mazzonna and Peracchi, 2016, 2012; Rohwedder and Willis, 2010), while studies focusing on mortality mostly find a reduction in mortality (Blake and Garrouste, 2013; Bloemen et al., 2017; Hallberg et al., 2015) or no significant effects (Hagen, 2017; Hernaes et al., 2013) with two studies reporting an increase in mortality after retirement (Fitzpatrick and Moore, 2018; Kuhn et al., 2010).
} 
mammography utilization (Dündar et al., 2006; Ferrat et al., 2013; Grunfeld et al., 2002; Lagerlund et al., 2000; Rakhshkhorshid et al., 2018). In addition, evidence shows that social network measured as the number of contact with family and friends as well as emotional social support (i.e., having someone to discuss personal concerns with) have a positive influence on mammography participation (Jensen et al., 2015). Taken together, those findings suggest that retirement may affect mammography through changes in breast cancer screening knowledge and perceptions since social networks change at retirement.

Previous studies show that retirement improves health behavior, and in particular those behaviors that require a time investment, e.g., exercise (Eibich, 2015; Insler, 2013; Kämpfen and Maurer, 2016; Motegi et al., 2016), sleep duration (Eibich, 2015; Motegi et al., 2016) and GP or specialist visits (Lucifora and Vigani, 2018). This suggests that retirement affects primary and secondary preventions through lower time constraints, since retirees have more leisure time available, which decreases the time costs of health investments.

Organized screening programs might interact with several of these potential mechanisms. Screening programs aim to reduce access barriers to healthcare by offering screening free of charge. Programs also reduce the time costs by inviting women directly for screening without the need to obtain a referral from their GP first. Lastly, the information provided alongside an invitation for screening in an organized program could affect women's perceptions of their cancer risk and of the benefit of screening (Martínez-Alonso et al., 2017; Woloshin et al., 2012). Therefore, it appears plausible that the effect of retirement on mammography use might differ between countries with a screening program and those without a program. 


\section{Contextual setting and data}

\subsection{Contextual setting}

\subsubsection{Breast cancer screening in Europe}

We focus on breast cancer screening for three reasons: First, breast cancer is the most common type of cancer in women worldwide (WHO, 2017a). The incidence of breast cancer is estimated to be 494,176 in Europe and 361,608 in the 28 countries of the European Union in 2012 (WHO, 2017b). Thus, 1 in 8 women in the EU-28 will develop breast cancer before the age of 85 (Ferlay et al., 2007). In 2015, roughly 91,585 women in the 28 countries of the European Union and 142,979 women in Europe died of breast cancer (WHO, 2017b). Second, breast cancer is most common in women above 50 years of age (WHO, 2017a), i.e., those women close to retirement or already retired. Third and last, if detected early, breast cancer is highly treatable with very high rates of survival. Survival rates depend crucially on the stage at which breast cancer is detected. Early screening increases the probability to detect a cancer at a more local stage, hence improving survival. The most common method for early detection of breast cancer is mammography - low dose X-ray imaging of the breasts. Based on evidence from clinical trials indicating that screening mammography reduces mortality by detecting tumors at an earlier stage (Marmot et al., 2013) expert organizations (World Health Organization's International Agency for Research on Cancer and the American Cancer Society) recommend regular, biennial screening mammograms starting at age 50 (Perry et al., 2008). Nearly every European country has now established a national breast cancer screening program (Altobelli and Lattanzi, 2014). The screening programs in Finland (1989), the UK (1995) and Sweden (1996) were introduced before the period covered in our empirical analysis (1996-2006, see Table A.1 in the online appendix). Between 1996 and 2006, national breast cancer screening programs were introduced in seven further countries, three of which are observed both before and after the introduction of the programs. All other countries, 
except Greece and Slovenia, have introduced a national screening program since 2006. Most countries provide free mammography for women aged over 50 years until 69 or 74 years old every two to three years, although a few countries offer screening from as early as 40 years. Such programs have successfully increased mammography use in Europe (Buchmueller and Goldzahl, 2018; Carrieri and Wuebker, 2016; Pletscher, 2017) and decreased mortality in the US and in the UK (Leive and Stratmann, 2015).

However, there is an ongoing debate about how the benefits of mammography (i.e., reduced mortality) should be weighed against the cost associated with false positive results and overdiagnosis possibly leading to overtreatment (Gøtzsche and Jørgensen, 2013). A U.K. expert panel conducted a meta-analysis of the randomized trial evidence and concluded that screening mammograms reduced the relative risk of mortality by $20 \%$, while acknowledging the problems of overdiagnosis and false-positive biopsies (Marmot et al., 2013). Recent evidence based on a discrete choice experiment showed that women would be willing to accept a higher ratio of overdiagnosis and false-positive biopsies for one life saved from breast cancer than the actual ratio estimated in the medical and epidemiological literature (Sicsic et al., 2017).

In the absence of a screening program, women can still have screening procedures but only through the usual healthcare pathways: for example, they might need a referral from a gynecologist or GP for a mammogram and then book an appointment with the radiologist. In some countries with a screening program (France, Switzerland, Luxemburg, Austria or Belgium), women within the age range can be screened in the program as well as outside the program: called opportunistic screening. Screening outside of the program might incur out-ofpocket expenditures. 


\subsubsection{Retirement eligibility}

The pension systems of most European countries involve both an Official Retirement Age (ORA) and an Early Retirement Age (ERA). The ORA represents the age at which all workers can claim a full old age pension, while the ERA offers specific subgroups the opportunity to retire at an earlier age. As pension eligibility might involve other criteria, ${ }^{5}$ our data does not allow us to ascertain pension eligibility on the individual level. Therefore, for the purpose of this study we define the ORA as the age at which all women are able to claim a pension, while the ERA is defined as the earliest age at which a woman might be eligible for a pension.

We use data on the ORA and ERA for each survey year and country from the database of the Mutual Information System on Social Protection (MISSOC, 2017). There is considerable variation in the ERA and ORA, both between countries as well as within countries over time. Further information on the pension ages used in this study is provided in Table A.1 in the online appendix.

\subsection{Data}

\subsubsection{Eurobarometer}

The analysis is based on data from the Eurobarometer. The Eurobarometer is a series of crosssectional surveys conducted on behalf of the European Commission. The surveys are conducted several times per year and include individuals from all current member states of the European Union. The surveys cover a range of different topics, which are based on current information needs of the European Commission and the European Parliament. Data from the Eurobarometer surveys are available to the scientific community via the Eurobarometer Data Service at GESIS (GESIS, 2017). The two main advantages of this survey compared to

\footnotetext{
${ }^{5}$ Retirement at the ORA might also involve a minimum period of social security contributions. In contrast, early retirement at the ERA might be limited to certain occupations or sectors. In addition, schemes offering an ERA might also involve a trade-off between an earlier retirement entry and a reduced pension.
} 
similar ones (such as the Survey of Health Ageing Retirement in Europe) is the availability of questions on preventive care utilization as well as on breast cancer perception in several waves. In addition, the cross-country nature of the survey enables us to investigate the heterogeneity of the effect of retirement by institutional settings such as the existence of a screening program.

\subsubsection{Outcomes}

For this paper, we use a set of questions on women's preventive healthcare use that was included five times between 1996 and $2006 .{ }^{6}$ These questions asked whether the woman had any of the following medical check-ups in the past 12 months: a mammography, a manual breast examination, a pap smear test (i.e., cervical cancer screening), an examination of the ovaries, a test for osteoporosis, or any other gynecological examination. Our focus is on mammography, since manual breast examinations are less effective at detecting early-stage breast cancer. Ovarian and cervical cancers are less common than breast cancer for the age group of interest. Furthermore, very few countries had cervical cancer screening programs (and none had programs for ovarian cancer) at the time of the survey and if they had one, the maximum age for eligibility would be 65 years old. Likewise, osteoporosis tests are rarely conducted and there are no screening programs for osteoporosis.

For the analysis of potential mechanisms, we also investigate women's belief concerning breast cancer prevention and treatment. In 1997 and 1998 only, women were asked whether they thought the following statements were true or false:

- "The sooner a cancer is detected, the better it can be treated.";

- “A mammography will detect signs of breast cancer.”;

- "There are effective treatments for breast cancer.";

\footnotetext{
${ }^{6}$ In detail, these are the EB44.3 (1996), EB47.2 (1997), EB49 (1998), EB59 (2003) and EB66.2 (2006). Questions on secondary preventive care for women were only introduced in these five waves of the Eurobarometer survey.
} 
- " "In most cases, you can be cured of breast cancer if it is detected early enough.";

- "Removal of the breast is the only way to be cured of breast cancer.".

Women were also asked whether they personally thought that cancer can be prevented.

\subsubsection{Retirement definition and covariates}

We define women as retired if their self-reported occupational status is either "retired", "permanently sick or injured", or "homemaker", since these women are unlikely to re-enter the labor market. In contrast, unemployed individuals are not considered to be retired, since they are looking for work and might re-enter the labor market. Unfortunately, we cannot distinguish between "retired" and "permanently sick or injured" in the Eurobarometer data, since these two option are in the same category (self-reported occupation as "retired or unable to work through illness"). We conduct robustness checks for including or excluding homemakers and unemployed women. To address selective labor market participation, we exclude women from the analysis who reported they had never done paid work. ${ }^{7}$

Age is measured in years. We control for education by including dummies for the age when finishing full-time education. The suggested categories are "15 or younger", "16 to 19”, "20 and above", and "still studying". While there are small differences in school starting age across countries, these categories should capture any major differences in education between individuals. Moreover, the primary purpose of these control variables is to account for correlations between educational attainment and state pension ages across countries as noted by Bingley and Martinello (2013).

We complement the survey data with information on state pension ages and existence and coverage of screening programs as discussed in the previous section (available in the

\footnotetext{
${ }^{7}$ This does not completely solve the issue of selective labor market participation. In particular, our sample might include women who permanently left the labor market after having children, and thus will not have done any paid work for a number of years. Unfortunately, we do not have any further information, e.g., when the respondent left their previous job.
} 
appendix in section A.1.). We restrict our working sample to women aged between 45 and 75 to ensure that for every country we include observations below the ERA and above the ORA. ${ }^{8}$ In addition, in some countries screening programs invite women from age 40 onwards, and almost all screening programs offer screening up to the age of 69 or 74 . Table A.2 in the appendix shows summary statistics for the working sample. We note that about $35 \%$ of the women had a mammography in the past 12 months, while $39 \%$ had a manual breast examination (i.e., either a self-examination or an examination by a clinician). Agreement to the statements on early detection, prevention and treatment of breast cancer was generally very high, with the exception of "Removal of the breast is the only way to be cured of breast cancer". However, it is worth noting that $40 \%$ of the women thought that cancer cannot be prevented. $35 \%$ of the women lived in a country with an organized screening program in the year of the survey.

\section{Methods}

In line with previous studies on retirement and health (see, e.g., Coe and Zamarro, 2011; Godard, 2016; Mazzonna and Peracchi, 2012), we exploit age thresholds for pension eligibility as a source of exogenous variation in retirement status in an instrumental variable estimation. These thresholds provide a financial incentive for individuals to postpone retirement until they have reached a certain age, since they are not able to draw upon their state pension beforehand. Given that the state pension ages vary between countries as well as within countries over time, they should not be correlated with unobserved confounders. Thus, we can use these state pension ages as instrumental variables for retirement.

\footnotetext{
${ }^{8}$ The ERA varies between 52 and 65 , while the ORA varies between 55 and 67 .
} 
Figure 1 shows the variation in state pension ages for each country in our sample over the study period. We note that there is considerable variation between countries. For example, throughout the study period, women in France could retire early at 55, while in Germany the early retirement age was 60 . Similarly, there is considerable variation within countries over time. While several countries raised their state pension ages (e.g., Italy increased the ERA from 52 in 1996 to 57 in 2006), there are also a few countries that lowered the ERA or ORA, respectively, e.g., Denmark or Portugal.

Figure 1 Variation in State Pension Ages
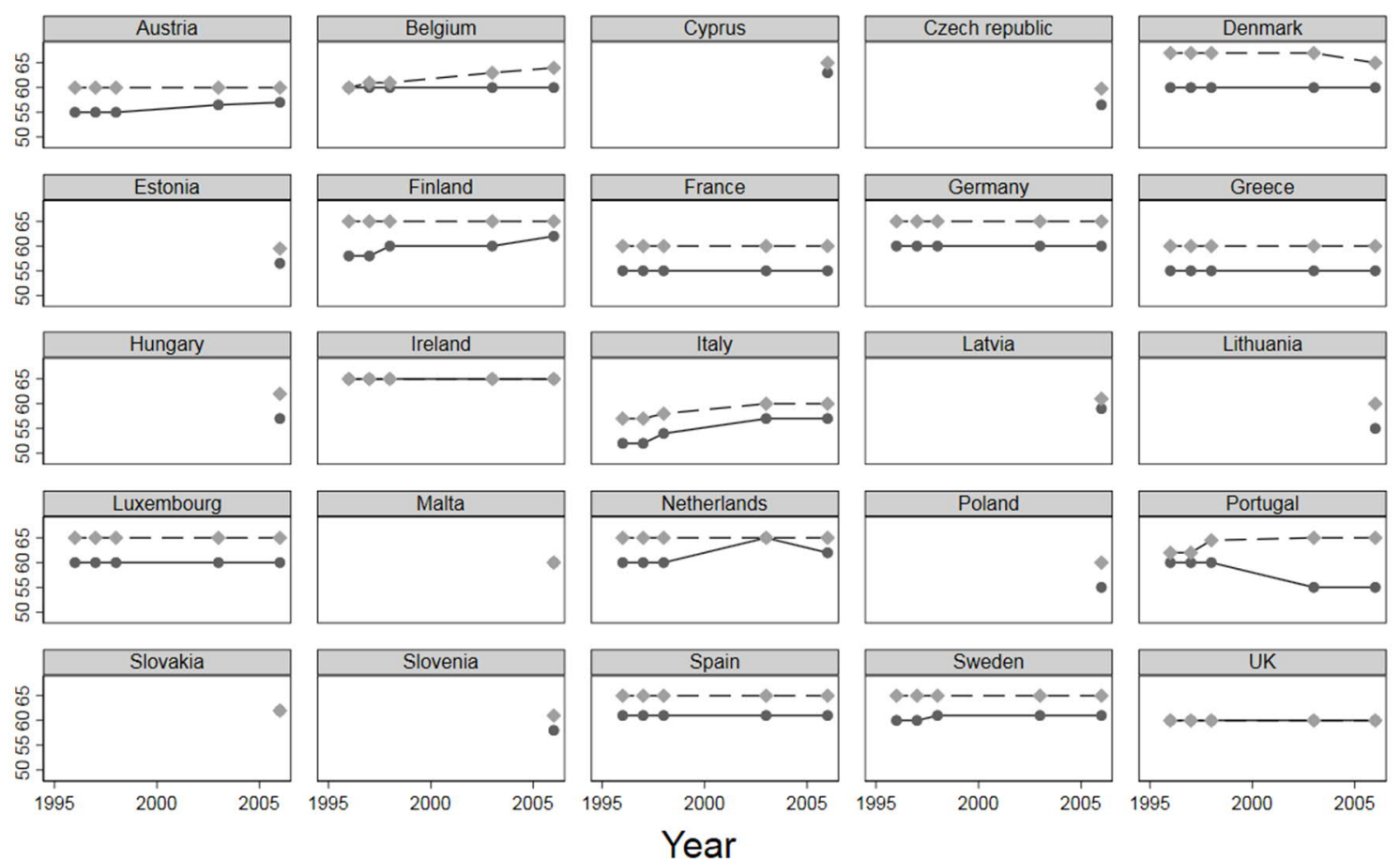

Year

\section{ERA Women $\quad----$ - ORA Women}

Graphs by Country

Source: Social protection in the member states of the European Union, MISSOC (1994, 1997, 1998, 2003), Celidoni and Rebba (2017), Euwals et al.(2010), Jousten et al.(2010), Mazzonna and Peracchi (2014) and Staubli and Zweimuller (2013).

We estimate linear probability models using two-stage least squares with binary indicators whether women have exceeded the relevant ERA or ORA in their countries as instruments for 
retirement. We control for a country-specific quadratic age trend ${ }^{9}$, four categories of education (finished full-time education at (i) 15 years or younger, (ii) between 16 and 19, (iii) at 20 years or older, (iv) still studying), and country-by-year fixed effects. ${ }^{10}$ The inclusion of additional covariates and fixed effects is not necessary for causal identification in IV models. IV estimation addresses all potential sources of bias as long as the necessary assumptions are met. ${ }^{11}$ Here, we included controls for education and country-by-year fixed effects to address the potential correlation between differences in pension eligibility ages across countries and education (Bingley and Martinello, 2013).

The resulting model can be written as follows:

$$
\begin{aligned}
& \text { retired }_{i}=\alpha+\left(\beta_{1} A g e_{i}+\beta_{2} A g e_{i}^{2}\right) \times c_{l, i}+\tau_{1} E R A_{i}+\tau_{2} O R A_{i}+\sum_{j=2}^{4} \delta_{j} E d u c_{j, i}+\sum_{k=2}^{85} \gamma_{k} c_{l, i} \times t_{w, i}+\varepsilon_{i} \\
& \text { Screen }_{i}=\mu+\left(\theta_{1} \text { Age }_{i}+\theta_{2} \text { Age }_{i}^{2}\right) \times c_{l, i}+\pi \text { Retired }_{i}+\sum_{j=1}^{4} \rho_{j} \text { Educ }_{j, i}+\sum_{k=2}^{85} \eta_{k} c_{l, i} \times t_{w, i}+v_{i}
\end{aligned}
$$

In the first stage of the model, we regress retirement of observation $i$ on binary indicators of whether women $i$ is above or below the ERA and ORA in country $l$ and year $w$, while controlling for a country-specific quadratic age trend, four binary indicators of education and 85 country-by-year fixed effects. In the second stage, we regress mammography use on the instrumented retirement status. We use two-way clustered standard errors to account for potential correlation of the error terms at the country-year level as well as by age. ${ }^{12}$

\footnotetext{
${ }^{9}$ We choose the age trend for our model based on goodness-of-fit. We consider linear, quadratic, cubic, countryspecific linear and country-specific quadratic age trends. The Akaike Information Criterion (AIC) indicates that a country-specific quadratic age trend provides the best fit. Results are available upon request.

${ }^{10}$ All estimations are done using the ivreg2-command in Stata 15, see Baum et al. (2002).

${ }^{11}$ These assumptions are: $(i)$ The instrument should be correlated with the treatment, (ii) the instrument should not affect the outcome except through its effect on the treatment, (iii) the instrument should have a monotone effect on the treatment. We will assess assumption (i) visually and statistically. We argue that assumption (ii) should hold conditionally on age. For assumption (iii), we argue that it is highly implausible that reaching age threshold for pension eligibility would reduce a women's likelihood to retire.

${ }^{12}$ For computational reasons, we partial out all exogenous regressors in the estimation.
} 
To examine effect heterogeneity between countries with and without a breast cancer screening program, we interact the retirement variable (as well as the instruments) with whether the woman lives in a country with a screening program. A threat to the identification of this effect is related to potential systematic differences in age specific breast cancer incidence or mortality between countries that adopt a program and those which don't. In that case, women living in countries with higher risk of breast cancer, which hence introduced a program, would get screened more often. Any difference that we would observe would be driven by differences in age-specific incidence and mortality rates rather than due to the program implementation (Carrieri and Wuebker, 2016). The epidemiological literature suggests that this is not the case as observed differences in incidence trends by countries are due to the country-specific age structure (Bray et al., 2004). Furthermore, Althuis et al. (2005) use local registry data to compute incidence rates of the years 1993 to 1997, and national data for mortality rates. Although they don't cover all European countries, there do not seem to be large differences in incidence and mortality rates between countries that had a program (the UK, Finland and Sweden) and those which did not (Italy, Spain and Denmark) at the time of the early survey waves.

\section{Results}

\subsection{Mammography use}

Table 1 presents the estimated effect of retirement on mammography use. The KleibergenPaap Wald F-statistics for weak instruments are above the often used value of 10 and suggest that the instruments are jointly significant as predictors of retirement status. ${ }^{13}$ Following a visual examination of the data (see Figures A.2 and A.3 in the appendix), we estimate two models - a basic model in which we estimate the effect of retirement across all countries, as

\footnotetext{
${ }^{13}$ The estimated coefficients for the instrumental variables in the first stage are reported in Table A.3 in the appendix.
} 
well as an interacted model, which contains an interaction between retirement and the existence of an organized screening program. 


\begin{tabular}{lcc}
\cline { 2 - 3 } Retired & $-0.251 * * *$ & $-0.268 * * *$ \\
& $(0.067)$ & $(0.065)$ \\
Retired x program & & 0.068 \\
& & $(0.056)$ \\
Wald F & & \\
Hansen's J & 35.6944 & 17.8341 \\
$\mathrm{~N}$ & 0.174 & 0.438 \\
\hline \hline
\end{tabular}

Sources: Eurobarometer, own calculations. All models include a country-specific quadratic age trend, education and country-by-year fixed effects. The interacted model includes a control variable for program existence and age range of the program. The sample includes women aged 45-75. Standard errors shown in parentheses are two-way clustered on country-year and age. $* * * \mathrm{p}<0.01 ; * * \mathrm{p}<0.05 ; * \mathrm{p}<0.1$.

The estimated effects show that being retired reduces the probability of mammography use by about 25 percentage points. The reduction in mammography use upon retirement is 6.8 percentage points lower in countries with an organized screening program. However, this estimate is not statistically significant. The interacted model suggests that the negative main effect of retirement clearly dominates and is not mitigated by the existence of an organized screening program.

To put the effect size into perspective, we note that mammography use declines by about 30 percentage points between the ages of 60 and 70 in our sample (Figure A.1 in the appendix). Moreover, the estimated causal effect of retirement is a local treatment effect, i.e., it only affects the complier population (those individuals who retire when reaching the ERA or ORA) - about $20 \%$ of the sample at the ERA and $9 \%$ to $12 \%$ of the sample at the ORA (see Table A.3 in the appendix). Hence, a reduction in mammography use by about 26 percentage point appears plausible. 
We systematically explore the sensitivity of our findings to (i) the age polynomial, (ii) country-specific age trends, (iii) the included age range, (iv) the definition of retirement status, and $(v)$ the exclusion of the observations within the first year after reaching the ERA/ORA. We estimate a wide range of models in a so-called specification curve analysis (Christensen and Miguel, 2018; Simonsohn et al., 2015) and conduct a permutation test. The results suggest that the negative effect of retirement on mammography use is generally robust to changes in the specification. The interaction effect between program existence and retirement is positive in all specifications, and it is significant in about a third of the specifications. Nevertheless, the results also suggest that the total effect of retirement on mammography use in countries with a screening program is still negative and significant. A detailed description of the approach and the results (together with additional placebo regressions) are provided in online appendix B. ${ }^{14}$

We also conduct two additional checks. First, we divide our sample into a group of countries that had an organized breast cancer screening program in all observed years as well as a group of countries that did not have an organized breast cancer screening program during the study period. We excluded four countries which are observed both before and after the introduction of their organized screening program. ${ }^{15}$ If the timing of the introduction of these screening programs were not exogenous, then the inclusion of these countries could bias our estimates. When we re-estimate our basic regression model for these two different groups of countries (Table A.4 in the appendix), the results are qualitatively comparable to the estimates presented in Table 1.

\footnotetext{
${ }^{14}$ In unreported regressions, we also estimate two more saturated models, which include age-year fixed effects and age-country fixed effects, respectively. While the standard errors increase considerably due to the large number of additional coefficients, the point estimates remain stable. We interpret this as further evidence for the robustness of our results. These estimates are available upon request.

${ }^{15}$ These countries are Belgium, France, the Netherlands, and Portugal. While Hungary, Lithuania and Cyprus introduced their screening program during the study period, we only observe these countries in 2006 (i.e., after the introduction of their program).
} 
Similarly, we divide our sample into two groups based on variation in the state pension ages. Countries in the first group did not change their ERA or ORA during the study period, while the second group consists of countries who changed either the ERA or ORA. As before, we find qualitatively similar effects in both groups of countries.

\subsection{Other secondary preventive care procedures}

We further extend our analysis by investigating the effect of retirement on other preventive healthcare procedures such as manual breast examinations, ovary examinations, pap smear tests, osteoporosis tests as well as any other gynecological examination. The estimated effects in Table 2 are negative and statistically significant for almost all tests, with the exception of osteoporosis tests. This is likely due to the fact that osteoporosis tests are relatively uncommon - only $16 \%$ of the women reported that they had an osteoporosis test done in the last 12 months. $^{16}$

\footnotetext{
${ }^{16}$ We can use the formula for randomized trials with imperfect compliance to calculate the minimum detectable effect (MDE) for this outcome at $80 \%$ power and a 95\% significance level. This provides us with an MDE of 0.055 , which is very close to the point estimate in Table 2 . The MDE calculation, however, involves a number of simplifying assumptions. Crucially, it does not account for the inclusion of covariates, which are correlated with treatment assignment (e.g., age). These covariates are likely to further increase the MDE, and thus it is not clear whether we would be able to reliably detect significant effects of the magnitude reported for osteoporosis tests in Table 2.
} 
Table 2: Secondary outcomes

$\begin{array}{ccccc}\begin{array}{c}\text { Manual } \\ \text { breast }\end{array} & \begin{array}{c}\text { Ovary } \\ \text { examination }\end{array} & \begin{array}{c}\text { Pap } \\ \text { smear } \\ \text { examination }\end{array} & \begin{array}{c}\text { Osteoporosis } \\ \text { test }\end{array} & \begin{array}{c}\text { Any other } \\ \text { gynecological } \\ \text { examination }\end{array}\end{array}$

\begin{tabular}{lccccc} 
Retired & $-0.199 * * *$ & $-0.193 * * *$ & $-0.168 * * *$ & -0.05 & $-0.187 * * *$ \\
& $(0.045)$ & $(0.062)$ & $(0.052)$ & $(0.047)$ & $(0.048)$ \\
& & & & & \\
Wald F & 36.305 & 35.176 & 35.686 & 58.311 & 36.304 \\
$\mathrm{~N}$ & 17,865 & 17,804 & 17,850 & 17,788 & 17,868 \\
\hline \hline
\end{tabular}

Sources: Eurobarometer, own calculations. All models include controls for education, country-by-year fixed effects as well as a country-specific quadratic age trend. The sample includes women aged 45-75. For all outcomes women were asked whether they had the examination done in the past 12 months. Standard errors are clustered by country-year and age. $* * * \mathrm{p}<0.01 ; * * \mathrm{p}<0.05 ; * \mathrm{p}<0.1$.

\section{Mechanisms}

First, we investigate whether the effect of retirement on mammography use operates

indirectly through changes in income or health status (Table A.6 in the appendix). Our results suggest that retirement has a positive effect on self-reported health, but this effect is not large enough to compensate the strong negative direct effect of retirement on mammography use. ${ }^{17}$

The effect of retirement on income is not significant in our model, most likely due to the broad income categories used in the model.

\footnotetext{
${ }^{17}$ It should be noted that this analysis does not account for endogeneity of health or income as potential mediators. This might introduce some bias, and thus the results cannot be interpreted as causal. Nevertheless, we argue that these findings provide suggestive evidence against health or income as mediators. For example, even though we find a positive (causal) effect of retirement on good health, and a negative association between good health and screening participation, the estimated effects are too small to account for a meaningful proportion of the negative effect of retirement on mammography use. Even if we could account for the potential endogeneity of health as a mediator, the estimated effect of health on mammography use would have to increase by a factor of 4 or more to explain more than $15 \%$ of the total effect of retirement on mammography use. We argue that this is highly unlikely, and therefore we conclude that health is unlikely to be a relevant mechanism. A similar argument holds for income, however, here the broad income categories present an additional limitation.
} 
Next, we examine whether the negative effect of retirement on mammography use can be explained by lower health insurance coverage, e.g., due to the loss of employer-sponsored complementary health insurance, large-scale workplace-based screening programs or incentive schemes. Unfortunately, there is no available data describing these features for all European countries for the time periods of interest. Therefore, we conduct a surrogate analysis. We exploit heterogeneity in the coverage of Social Health Insurance (SHI) at the country level to examine the role of (potentially employer-sponsored) complementary health insurance coverage. All European countries in our study have a SHI system that covers a large share of healthcare expenditures for both working and retired individuals. In countries where all expenditures are covered by SHI retirement should not affect healthcare access, since complementary health insurance plays no role in providing access to healthcare. In contrast, we would expect that the effect of retirement on secondary preventive care use is more pronounced in countries with a lower share of costs covered by SHI, since complementary health insurance is (relatively) more important in providing access to secondary preventive care. Hence, we investigate heterogeneity across institutional settings based on differences in coverage of SHI. We use OECD data on healthcare expenditures (OECD, 2017) by year covering 23 out of the 25 countries in our analysis. ${ }^{18} \mathrm{We}$ construct an indicator for "SHI coverage", which we define as the ratio of government and compulsory healthcare expenditures to total healthcare expenditures for each year of the survey. A value of 1 would indicate that all healthcare expenditures are covered by the SHI system (e.g., tax financed as in the UK, or funded by compulsory health insurance schemes as in Germany), while a value of 0 indicates that all healthcare expenditures are voluntary (i.e., either out-of-pocket payments or covered by private health insurance schemes). In our sample, this indicator ranges from 0.49 to 0.92 . Then, we divide the sample based on the median value of this

\footnotetext{
${ }^{18}$ There are no data on Malta and Cyprus.
} 
indicator by year into a subsample with lower SHI coverage and a subsample with higher SHI coverage. ${ }^{19}$ The results in Table 3 indicate that the reduction in mammography use following retirement is driven by countries with lower SHI coverage of healthcare expenditures. This indicates that transitioning out of employment has a larger effect in countries where complementary health insurance covers a larger share of healthcare expenditures. This effect is not mitigated by the existence of organized screening programs.

Table 3: The effect of retirement on mammography use Lower public coverage Higher public coverage

$\begin{array}{cccc}\text { Mammography } & \text { Mammography } & \text { Mammography } & \text { Mammography } \\ \text { use in the past } & \text { use in the past } & \text { use in the past } & \text { use in the past } \\ 12 \text { months } & 12 \text { months } & 12 \text { months } & 12 \text { months }\end{array}$

\section{Retired} $-0.523 * * *$ $-0.584 * * *$ $-0.095$ $-0.121 * *$ $(0.115)$ $(0.127)$ (0.069)

\section{Retired $x$ program}

$\begin{array}{lcccc}\text { Wald F } & 22.6 & 10.5 & 26.4 & 7.9 \\ \text { Hansen's } & 0.289 & 0.529 & 1.063 & 0.334 \\ \mathrm{~J} & 8,154 & 8,154 & 9,419 & 9,419 \\ \mathrm{~N} & & \end{array}$

Sources: Eurobarometer, OECD Health data, own calculations. All models include controls for education, country-by-year fixed effects as well as a country-specific quadraticage trend. All models include women aged 45 to 75 . Standard errors are clustered by country-year and age. $* * * \mathrm{p}<0.01 ; * * \mathrm{p}<0.05 ; * \mathrm{p}<0.1$.

\footnotetext{
${ }^{19}$ The sample with lower SHI coverage includes Estonia, Spain, Finland, Greece, Hungary, Lithuania, Latvia, Poland, Portugal, Slovenia and Slovakia in all years. The sample with higher SHI coverage includes Czech Republic, Germany, Denmark, France, UK, Luxembourg and Sweden in all years. The remaining countries (Austria, Belgium, Ireland, Italy and The Netherlands) change groups across the years.
} 
Table 4: Retirement and cancer beliefs

\begin{tabular}{|c|c|c|c|c|c|}
\hline $\begin{array}{l}\text { The sooner a } \\
\text { cancer is } \\
\text { detected, the } \\
\text { better it can } \\
\text { be treated. }\end{array}$ & $\begin{array}{l}\text { A mammography will } \\
\text { detect signs of breast } \\
\text { cancer. }\end{array}$ & $\begin{array}{l}\text { There are } \\
\text { effective } \\
\text { treatments for } \\
\text { breast cancer. }\end{array}$ & $\begin{array}{c}\text { In most } \\
\text { cases, you } \\
\text { can be cured } \\
\text { of breast } \\
\text { cancer if it is } \\
\text { detected } \\
\text { early } \\
\text { enough. }\end{array}$ & $\begin{array}{l}\text { Removal of } \\
\text { the breast is } \\
\text { the only way } \\
\text { to be cured of } \\
\text { breast cancer. }\end{array}$ & $\begin{array}{c}\text { Do you } \\
\text { personally think } \\
\text { that cancer } \\
\text { cannot be } \\
\text { prevented? }\end{array}$ \\
\hline$-0.106 * *$ & 0.038 & $-0.205^{* * *}$ & 0.068 & 0.087 & $0.193 * *$ \\
\hline (0.046) & $(0.038)$ & $(0.066)$ & $(0.059)$ & $(0.124)$ & (0.094) \\
\hline 13.431 & 12.992 & 12.293 & 13.417 & 11.460 & 13.550 \\
\hline 5,346 & 5,216 & 4,743 & 5,029 & 4,625 & 5,107 \\
\hline
\end{tabular}

\begin{tabular}{llllll}
$\mathrm{N}$ & 5,346 & 4,216 & 5,029 & 4,625 & 5,107 \\
\hline Sources: Eurobarometer, own calculations. All models include controls for education,country-by-year fixed effects as well as a country-specific
\end{tabular} quadratic age trend. The sample includes women aged 45-75. The outcome variables are binary indicators showing whether respondents agreed or disagreed with the statement. Standard errors are clustered by country-year and age. $* * * p<0.01 ; * * p<0.05 ; * p<0.1$. 
Retirement might affect knowledge and perceptions of cancer prevention through, e.g., changes in social networks or social interactions after retirement. In Table 4, we examine the effect of retirement on women's perceptions and knowledge concerning breast cancer prevention and treatment. The results indicate that retirement negatively affects women's perceptions of breast cancer prevention and treatment. Retired women are 11 percentage points less likely to agree that early detection will result in better treatment for breast cancer. They are 21 percentage points less likely to agree that there are effective treatments for breast cancer, and the likelihood that they thought that cancer can be prevented was reduced by 19 percentage points. All estimates are significant at the $5 \%$ level. $^{20}$

\section{Discussion}

We analyze the effect of retirement on mammography use using data from 25 European countries. We address the endogeneity of retirement by using state pension ages for early and official retirement as instruments. Our findings show that retirement reduces mammography use by about 26 percentage points. Organized screening programs might mitigate the negative impact of retirement to some degree, but the overall effect of retirement is still negative.

Retirement also reduces the use of other preventive health check-ups, such as manual breast examinations, ovary examinations, or pap smear tests. However, the reduction is considerably smaller than the effect of retirement on mammography use. A mammography typically requires an appointment with a radiologist or a specialized mammography unit, while, e.g., manual breast examinations or pap smear tests can be conducted during a regular consultation with a GP or gynecologist. This might explain why the latter procedures are less strongly affected by retirement. Nonetheless, our results suggest that the negative effect of retirement is neither specific to mammography nor to breast cancer. Our evidence does not suggest that

\footnotetext{
${ }^{20}$ It should be noted that we control for education as well as country-by-year fixed effects, and therefore these results are unlikely to be confounded by cohort effects.
} 
the reduction in mammography use is driven by changes in health or income. We find that the negative effect of retirement is stronger in countries with lower SHI coverage of healthcare expenditures, which suggests that access to health care (e.g., due to employer-sponsored complementary health insurance) might partly explain the negative effect. However, we also note that our indicator of healthcare coverage is only a proxy measure, which might also pick up other differences across countries. We also find that retirement negatively affects women's perceptions on breast cancer prevention and treatment. We argue that it is highly likely that such perceptions are malleable, especially given that previous studies report consistently negative effects of retirement on cognitive functioning (see, e.g., Bingley \& Martinello, 2013; Bonsang, Adam, \& Perelman, 2012; Mazzonna \& Peracchi, 2012; Rohwedder \& Willis, 2010). Such changes in knowledge and perceptions of breast cancer prevention and treatment could be caused by a change in the size and composition of social networks upon retirement. Social interactions are considered to be a major determinants of screening uptake (Fadlon and Nielsen, 2019). The transition out of the labor force is likely to affect both the size and the composition of the social networks, such that retirees might be more likely to interact with family members and older peers rather than with younger colleagues. Consequently, they might be more likely to experience cancer diagnoses and (unsuccessful) treatment in their social network, which in turn affects their perceptions of cancer prevention and treatment. This mechanism is in line with the Health Belief Model, which emphasizes the role of perceived risks and benefits for the adoption of health-promoting behavior. Our results are also in line with the health capital model (Galama et al., 2013; Grossman, 1972), which suggests that retirees have fewer incentives to invest in their health and will reallocate some of their health investments into consumption. It appears plausible that this effect would be more pronounced for preventive healthcare (such as cancer screening) than for curative healthcare. While our results are consistent with this hypothesis, we cannot draw any definite 
conclusions using reduced-form models. Our results also show that even in countries with an organized breast cancer screening program retirement reduces mammography use. Thus, policy makers might need to consider additional measures, such as targeted provision of health information or a reduction in (financial) access barriers to healthcare, to increase preventive care use at older ages.

The Eurobarometer data used in this analysis has several important strengths and limitations. A major strength of the data is that it includes information on secondary preventive care use as well as beliefs and perceptions of breast cancer prevention and treatment for 25 different European countries. Secondary preventive care use is rarely covered in comparable household surveys. For example, SHARE only includes information on breast cancer screening in wave 2. Moreover, beliefs and perceptions of cancer are (to the best of our knowledge) not covered in any comparable datasets. Unfortunately, the design of the Eurobarometer as a repeated cross-section means that we cannot examine changes within individuals over time. While panel data methods are not required for the validity of our IV design, it would be very interesting to explore the malleability of these cancer beliefs and perceptions within individuals.

It should be noted that the data covers the period of 1996 to 2006. This is, on the one hand, a very interesting study period due to the variation in pension eligibility ages and breast cancer screening programs between countries as well as within countries over time. However, it also raises the question whether our findings are still relevant today. We argue that this is likely to be the case. First, we have no reason to assume that the underlying mechanisms between retirement and secondary preventive care use have changed substantially over the last decade. However, two important changes that might affect our conclusions are the implementation of breast cancer screening programs in almost all countries studied in this paper, as well as the increase in labor market participation among women.

Following the European Council's recommendation for population-based breast screening of women aged 50-69 years, almost all countries in the European Union have implemented programs, and existing screening programs have worked towards increasing their participation rates and coverage to reach the target rate of $75 \%$. This might suggest that organized screening programs now are more important in mitigating the negative effect of retirement on breast cancer screening. However, as of 2017 most countries failed to meet the 
target participation rate of 75\% (Ponti et al., 2017), which suggests that socioeconomic characteristics (such as employment) are still relevant determinants of participation.

Finally, labor market participation among older women is highly selective, in particular for earlier cohorts. This becomes, e.g., evident from the summary statistics in Table A.2, which show that our sample includes a relatively large number of highly educated women. However, over the past decade labor market participation rates of older women have increased in many countries, and labor market participation has become less selective. At the same time, educational attainment is higher in younger-born cohorts. Taken together, these trends suggest that today's population of women near retirement age in Europe might differ from our sample. Yet, it is not clear how such changes would affect the external validity of our findings. Participation in preventive care (Carrieri and Wuebker, 2013; Jusot et al., 2012) is higher among women with high education, and thus the potential impact of retirement on participation might be larger in this subgroup. At the same time, the relevant mechanisms proposed in this study (financial access barriers and changes in beliefs) are likely to be more relevant for women with lower education and socioeconomic status. Future research should examine how these changes and trends have affected the relationship between retirement and secondary preventive care use. 


\section{References}

Althuis, M.D., Dozier, J.M., Anderson, W.F., Devesa, S.S., Brinton, L.A., 2005. Global trends in breast cancer incidence and mortality 1973-1997. International Journal of Epidemiology 34, 405-412. https:/ / doi.org/ 10.1093/ ije/ dyh414

Altobelli, E., Lattanzi, A., 2014. Breast cancer in European Union: an update of screening programmes as of March 2014. International journal of oncology 45, 1785-1792.

Baum, C.F., Schaffer, M.E., Stillman, S., 2002. IVREG2: Stata module for extended instrumental variables/ 2SLS and GMM estimation. Boston College Department of Economics.

Berger, N.A., Savvides, P., Koroukian, S.M., Kahana, E.F., Deimling, G.T., Rose, J.H., Bowman, K.F., Miller, R.H., 2006. Cancer in the Elderly. Transactions of the American Clinical and Climatological Association $117,147-156$.

Berkman, L.F., Glass, T., 2000. Social Integration, Social Networks, Social Support, and Health, in: Berkman, L.F., Kawachi, I. (Eds.), Social Epidemiology. Oxford University Press, New York, pp. 137-173.

Bingley, P., Martinello, A., 2013. Mental retirement and schooling. European Economic Review 63, 292298. https:/ / doi.org/ 10.1016/ j.euroecorev.2013.01.004

Blake, H., Garrouste, C., 2013. Killing me softly: work and mortality among French seniors (Health, Econometrics and Data Group (HEDG) Working Paper). HEDG, c/ o Department of Economics, University of York.

Bloemen, H., Hochguertel, S., Zweerink, J., 2017. The causal effect of retirement on mortality: Evidence from targeted incentives to retire early. Health Economics n/ a-n/ a. https:/ / doi.org/ 10.1002/ hec.3493

Bonsang, E., Adam, S., Perelman, S., 2012. Does retirement affect cognitive functioning? Journal of Health Economics 31, 490-501. https:// doi.org/ 10.1016/j.jhealeco.2012.03.005

Börsch-Supan, A., Schuth, M., 2013. Early Retirement, Mental Health, and Social Networks, in: Discoveries in the Economics of Aging. University of Chicago Press, pp. 225-250.

Bouckaert, N., Schokkaert, E., 2016. Differing types of medical prevention appeal to different individuals. Eur J Health Econ 17, 317-337. https:/ / doi.org/ 10.1007/ s10198-015-0709-6

Bray, F., McCarron, P., Parkin, D.M., 2004. The changing global patterns of female breast cancer incidence and mortality. Breast Cancer Res 6, 229-239. https:/ / doi.org/ 10.1186/ bcr932

Buchmueller, T.C., Goldzahl, L., 2018. The effect of organized breast cancer screening on mammography use: Evidence from France. Health Economics 27, 1963-1980. https:/ / doi.org/ 10.1002/ hec.3813

Carrieri, V., Wuebker, A., 2016. Quasi-Experimental Evidence on the Effects of Health Information on Preventive Behaviour in Europe. Oxford Bulletin of Economics and Statistics 78, 765-791.

Carrieri, V., Wuebker, A., 2013. Assessing inequalities in preventive care use in Europe. Health Policy 113, 247-257. https:/ / doi.org/ 10.1016/j.healthpol.2013.09.014

Celidoni, M., Rebba, V., 2017. Healthier lifestyles after retirement in Europe? Evidence from SHARE. Eur J Health Econ 18, 805-830. https:/ / doi.org/ 10.1007/ s10198-016-0828-8

Christensen, G., Miguel, E., 2018. Transparency, Reproducibility, and the Credibility of Economics Research. Journal of Economic Literature 56, 920-80. https:/ / doi.org/ 10.1257/ jel.20171350

Coe, N.B., Zamarro, G., 2015. Does Retirement Impact Health Care Utilization? (SSRN Scholarly Paper No. ID 2714144). Social Science Research Network, Rochester, NY.

Coe, N.B., Zamarro, G., 2011. Retirement effects on health in Europe. Journal of Health Economics 30, 7786. https:/ / doi.org/ 10.1016/j.jhealeco.2010.11.002

Courtney-Long, E., Armour, B., Frammartino, B., Miller, J., 2011. Factors associated with self-reported mammography use for women with and women without a disability.J Womens Health (Larchmt) 20, 1279-1286. https:// doi.org/ 10.1089/jwh.2010.2609

De Grip, A., Lindeboom, M., Montizaan, R., 2011. Shattered Dreams: The effects of changing the pension system late in the game. Economic Journal 122, 1-25.

Dündar, P.E., Ozmen, D., Oztürk, B., Haspolat, G., Akyildiz, F., Coban, S., Cakiroglu, G., 2006. The knowledge and attitudes of breast self-examination and mammography in a group of women in a rural area in western Turkey. BMC Cancer 6, 43-43. https:/ / doi.org/ 10.1186/ 1471-2407-6-43

Eibich, P., 2015. Understanding the effect of retirement on health: Mechanisms and Heterogeneity. Journal of Health Economics 43, 1-12. https:/ / doi.org/ 10.1016/j.jhealeco.2015.05.001

Euwals, R., van Vuuren, D., Wolthoff, R., 2010. Early Retirement Behaviour in the Netherlands: Evidence From a Policy Reform. De Economist 158, 209-236. https:/ / doi.org/ 10.1007/ s10645-010-9139-0

Fadlon, I., Nielsen, T.H., 2019. Family Health Behaviors. American Economic Review 109, 3162-91. https:/ / doi.org/ 10.1257/ aer.20171993

Ferlay, J., Autier, P., Boniol, M., Heanue, M., Colombet, M., Boyle, P., 2007. Estimates of the cancer incidence and mortality in Europe in 2006. Annals of oncology 18, 581-592. 
Ferrat, E., Le Breton, J., Djassibel, M., Veerabudun, K., Brixi, Z., Attali, C., Renard, V., 2013. Understanding barriers to organized breast cancer screening in France: women's perceptions, attitudes, and knowledge. Fam Pract 30, 445-451. https:/ / doi.org/ 10.1093/ fampra/ cmt004

Fitzpatrick, M.D., Moore, T.J., 2018. The mortality effects of retirement: Evidence from Social Security eligibility at age 62. Journal of Public Economics 157, 121-137. https:/ / doi.org/ 10.1016/ j.jpubeco.2017.12.001

Fletcher, J.M., 2014. Late life transitions and social networks: The case of retirement. Economics Letters, Economics Letters 125, 459-462. https:/ / doi.org/ 10.1016/ j.econlet.2014.10

Frimmel, W., Pruckner, G., 2018. Retirement and healthcare utilization. Verein für Socialpolitik / German Economic Association.

Galama, T., Kapteyn, A., Fonseca, R., Michaud, P.-C., 2013. A health production model with endogenous retirement. Health Economics 22, 883-902. https:/ / doi.org/ 10.1002/ hec.2865

Gandhi, P.K., Gentry, W.M., Kibert, J.L., Lee, E.Y., Jordan, W., Bottorff, M.B., Huang, I.-C., 2015. The relationship between four health-related quality-of-life indicators and use of mammography and Pap test screening in US women. Qual Life Res 24, 2113-2128. https:/ / doi.org/ 10.1007/ s11136015-0968-9

GESIS, 2017. Eurobarometer Data Service [WWW Document]. URL https:/ / www.gesis.org/ eurobarometer-data-service/ home/ (accessed 10.12.17).

Godard, M., 2016. Gaining weight through retirement? Results from the SHARE survey. Journal of Health Economics 45, 27-46. https:/ / doi.org/ 10.1016/ j.jhealeco.2015.11.002

Gøtzsche, P.C., Jørgensen, K.J., 2013. Screening for breast cancer with mammography. The Cochrane Library.

Grossman, M., 1972. On the Concept of Health Capital and the Demand for Health. Journal of Political Economy 80, 223-255.

Grøtting, M.W., Lillebø, O.S., 2017. Health effect of retirement. Evidence from Norwegian Survey and Register Data. University of Bergen, Working Papers in Economics No. 2/ 17.

Grunfeld, E.A., Ramirez, A.J., Hunter, M.S., Richards, M.A., 2002. Women's knowledge and beliefs regarding breast cancer. Br J Cancer 86, 1373-1378. https:/ / doi.org/ 10.1038/ sj.bjc.6600260

Guilcher, S.J.T., Lofters, A., Glazier, R.H., Jaglal, S.B., Voth, J., Bayoumi, A.M., 2014. Level of disability, multimorbidity and breast cancer screening: does severity matter? Prev Med 67, 193-198. https:/ / doi.org/ 10.1016/ j.ypmed.2014.07.025

Hagen, J., 2017. The effects of increasing the normal retirement age on health care utilization and mortality.J Popul Econ 1-42. https:// doi.org/ 10.1007/ s00148-017-0664-x

Hallberg, D., Johansson, P., Josephson, M., 2015. Is an early retirement offer good for your health? Quasiexperimental evidence from the army. Journal of Health Economics 44, 274-285. https:/ / doi.org/ 10.1016/ j.jhealeco.2015.09.006

Hernaes, E., Markussen, S., Piggott, J., Vestad, O.L., 2013. Does retirement age impact mortality? Journal of Health Economics 32, 586-598. https:/ / doi.org/ 10.1016/j.jhealeco.2013.03.001

Insler, M., 2014. The Health Consequences of Retirement. J. Human Resources 49, 195- 233.

Insler, M., 2013. The Health Consequences of Retirement. US Naval Academy Department of Economics Working Paper 2013-43.

Jensen, L.F., Pedersen, A.F., Andersen, B., Vedsted, P., 2015. Self-assessed health, perceived stress and nonparticipation in breast cancer screening: A Danish cohort study. Prev Med 81, 392-398. https:/ / doi.org/ 10.1016/ j.ypmed.2015.10.004

Jousten, A., Lefèbvre, M., Perelman, S., Pestieau, P., 2010. The Effects of Early Retirement on Youth Unemployment: The Case of Belgium, in: Social Security Programs and Retirement around the World: The Relationship to Youth Employment. University of Chicago Press, pp. 47-76.

Jusot, F., Or, Z., Sirven, N., 2012. Variations in preventive care utilisation in Europe. European Journal of Ageing 9, 15-25. https:/ / doi.org/ 10.1007/ s10433-011-0201-9

Kämpfen, F., Maurer,J., 2016. Time to burn (calories)? The impact of retirement on physical activity among mature Americans. Journal of Health Economics 45, 91-102. https:/ / doi.org/ 10.1016/ j.jhealeco.2015.12.001

Kuhn, A., Wuellrich, J.-P., Zweimüller, J., 2010. Fatal attraction? Access to early retirement and mortality (IEW - Working Paper No. 499). Institute for Empirical Research in Economics - University of Zurich.

Lagerlund, M., Hedin, A., Sparén, P., Thurfjell, E., Lambe, M., 2000. Attitudes, Beliefs, and Knowledge as Predictors of Nonattendance in a Swedish Population-Based Mammography Screening Program. Preventive Medicine 31, 417-428. https:/ / doi.org/ 10.1006/ pmed.2000.0723 
Leive, A., Stratmann, T., 2015. Do national cancer screening guidelines reduce mortality? Journal of Population Economics 28, 1075-1095. https:/ / doi.org/ 10.1007/ s00148-014-0536-6

Lucifora, C., Vigani, D., 2018. Health care utilization at retirement: The role of the opportunity cost of time. Health Economics 27, 2030-2050. https:/ / doi.org/ 10.1002/ hec.3819

Marmot, M., Altman, D., Cameron, D., Dewar, J., Thompson, S., Wilcox, M., Screening, I.U.P. on B.C., others, 2013. The benefits and harms of breast cancer screening: an independent review. British journal of cancer 108, 2205.

Martínez-Alonso, M., Carles-Lavila, M., Pérez-Lacasta, M.J., Pons-Rodríguez, A., Garcia, M., Rué, M., 2017. Assessment of the effects of decision aids about breast cancer screening: a systematic review and meta-analysis. BMJ Open 7. https:/ / doi.org/ 10.1136/ bmjopen-2017-016894

Mazzonna, F., Peracchi, F., 2016. Unhealthy Retirement? J. Human Resources. https:// doi.org/ 10.3368/ jhr.52.1.0914-6627R1

Mazzonna, F., Peracchi, F., 2014. Unhealthy retirement? Evidence of occupation heterogeneity. USI Università della Svizzera italiana.

Mazzonna, F., Peracchi, F., 2012. Ageing, cognitive abilities and retirement. European Economic Review 56, 691-710.

MISSOC, 2017. Comparative tables [WWW Document]. URL http:/ / www.missoc.org/ INFORMATIONBASE/ COMPARATIVETABLES/ MISSOCDATABASE/ comp arativeTableSearch de.jsp (accessed 10.11.17).

Motegi, H., Nishimura, Y., Terada, K., 2016. Does Retirement Change Lifestyle Habits? The Japanese Economic Review 67, 169-191. https:/ / doi.org/ 10.1111/ jere.12104

Nishimura, Y., Oikawa, M., Motegi, H., 2017. What Explains the Difference in the Effect of Retirement on Health? Evidence from Global Aging Data. Journal of Economic Surveys forthcoming. https:/ / doi.org/ 10.1111/ joes.12215

OECD, 2017. Health at a Glance 2017.

Patacchini, E., Engelhardt, 2016. Work, Retirement, and Social Networks at Older Ages. Center for Retirement Research.

Perry, N., Broeders, M., de Wolf, C., Törnberg, S., Holland, R., von Karsa, L., 2008. European guidelines for quality assurance in breast cancer screening and diagnosis. - summary document. Annals of Oncology 19, 614-622.

Pletscher, M., 2017. The effects of organized screening programs on the demand for mammography in Switzerland. The European Journal of Health Economics 18, 649-665.

Ponti, A., Anttila, A., Ronco, G., Senore, C., Basu, P., Segnan, N., Tomatis, M., Žakelj, M.P., Dillner, J., Fernan, M., Elfström, K.M., Lönnberg, S., Soerjomataram, I., Sankaranaryanan, R., Vale, D., 2017. Cancer Screening in the European Union (2017): Report on the implemention of the Council Recommendation on cancer screening. European Commission.

Rakhshkhorshid, M., Navaee, M., Nouri, N., Safarzaii, F., 2018. The Association of Health Literacy with Breast Cancer Knowledge, Perception and Screening Behavior. Eur J Breast Health 14, 144-147. https:/ / doi.org/ 10.5152/ ejbh.2018.3757

Rohwedder, S., Willis, RJ., 2010. Mental retirement. The journal of economic perspectives 24, 119-138.

Sicsic, J., Pelletier-Fleury, N., Moumjid, N., 2017. Women's Benefits and Harms Trade-Offs in Breast Cancer Screening: Results from a Discrete Choice Experiment. Value in Health. https:/ / doi.org/ 10.1016/ j.jval.2017.07.003

Simonsohn, U., Simmons, J.P., Nelson, L.D., 2015. Specification Curve: Descriptive and Inferential Statistics on All Reasonable Specifications (SSRN Scholarly Paper No. ID 2694998). Social Science Research Network, Rochester, NY.

Staubli, S., Zweimüller, J., 2013. Does raising the early retirement age increase employment of older workers? Journal of Public Economics 108, 17-32. https:/ / doi.org/ 10.1016/ j.jpubeco.2013.09.003

WHO, 2017a. Breast cancer: prevention and control [WWW Document]. URL http:/ / www.who.int/ cancer/ detection/ breastcancer/ en/ index1.html (accessed 10.12.17).

WHO, 2017b. Cancer Fact Sheets: Breast Cancer [WWW Document]. URL http:/ / gco.iarc.fr/ today/ factsheets-cancers?cancer $=15 \&$ type $=1 \&$ sex $=2$ (accessed 12.21.17).

Woloshin, S., Schwartz, L.M., Black, W.C., Kramer, B.S., 2012. Cancer Screening Campaigns - Getting Past Uninformative Persuasion. New England Journal of Medicine 367, 1677-1679. https:/ / doi.org/ 10.1056/ NEJMp1209407

$\mathrm{Wu}, \mathrm{S} ., 2003$. Sickness and preventive medical behavior. Journal of health economics 22, 675-689. 
Zantinge, E.M., van den Berg, M., Smit, H.A., Picavet, H.S.J., 2014. Retirement and a healthy lifestyle:

opportunity or pitfall? A narrative review of the literature. European Journal of Public Health 24, 433-439. 


\section{Online appendix}

A. Supplementary Figures and Tables

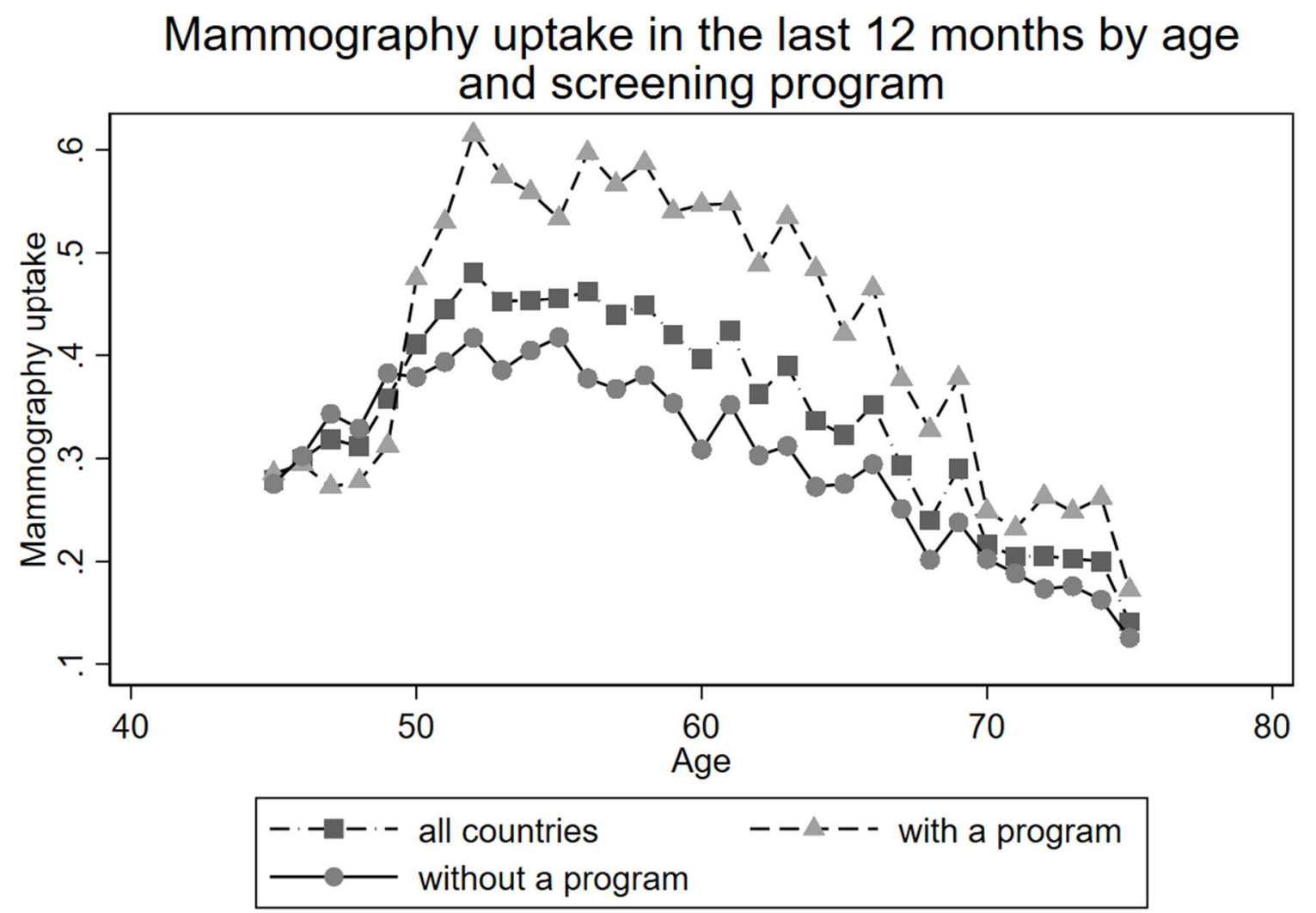

Fig. A.1 Mammography uptake in the last 12 months by age. Source: Eurobarometer, own calculations. 
Table A1: Retirement ages and screening programs in Europe

\begin{tabular}{|c|c|c|c|c|c|c|c|c|c|c|c|c|}
\hline \multirow{3}{*}{ Survey years } & \multicolumn{10}{|c|}{ Retirement ages of European women } & \multirow{2}{*}{\multicolumn{2}{|c|}{$\begin{array}{c}\text { Breast cancer Screening program } \\
\text { characteristics }\end{array}$}} \\
\hline & \multicolumn{2}{|c|}{1996} & \multicolumn{2}{|c|}{1997} & \multicolumn{2}{|c|}{1998} & \multicolumn{2}{|c|}{2003} & \multicolumn{2}{|c|}{2006} & & \\
\hline & ERA & ORA & ERA & ORA & ERA & ORA & ERA & ORA & ERA & ORA & $\begin{array}{l}\text { Year of implementation } \\
\text { (nationwide coverage) }\end{array}$ & Age range \\
\hline \multicolumn{13}{|c|}{ A. Screening program introduced before observed period (pre-1996) } \\
\hline Finland & 58 & 65 & 58 & 65 & 60 & 65 & 60 & 65 & 62 & 65 & 1989 & $50-69$ \\
\hline Luxembourg & 60 & 65 & 60 & 65 & 60 & 65 & 60 & 65 & 60 & 65 & 1992 & $50-69$ \\
\hline UK & 60 & 60 & 60 & 60 & 60 & 60 & 60 & 60 & 60 & 60 & 1995 & $50-70^{\mathrm{b}}$ \\
\hline Sweden & 60 & 65 & 60 & 65 & 61 & 65 & 61 & 65 & 61 & 65 & $1996^{\mathrm{a}}$ & $40-74$ \\
\hline \multicolumn{13}{|c|}{ B. Screening program introduced during observed period (1996-2006) } \\
\hline Netherlands & 60 & 65 & 60 & 65 & 60 & 65 & 65 & 65 & 62 & 65 & $1997^{\mathrm{a}}$ & $50-74^{\mathrm{c}}$ \\
\hline Belgium & 60 & 60 & 60 & 61 & 60 & 61 & 60 & 63 & 60 & 64 & 2001 & $50-69$ \\
\hline Hungary & & & & & & & & & 57 & 62 & 2002 & $45-65$ \\
\hline France & 55 & 60 & 55 & 60 & 55 & 60 & 55 & 60 & 55 & 60 & $2004^{\mathrm{a}}$ & $50-74$ \\
\hline Lithuania & & & & & & & & & 55 & 60 & 2005 & $50-69$ \\
\hline Portugal & 60 & 62 & 60 & 62 & 60 & 64.5 & 55 & 65 & 55 & 65 & $2005^{\mathrm{a}}$ & $45-69$ \\
\hline Cyprus & & & & & & & & & 63 & 65 & $2006^{\mathrm{a}}$ & $50-69$ \\
\hline \multicolumn{13}{|c|}{ C. Screening program introduced after observed period (post-2006)/no existing screening program } \\
\hline Czech republic & & & & & & & & & 56.5 & 59.8 & $2007^{\mathrm{a}}$ & $45-69$ \\
\hline Estonia & & & & & & & & & 56.5 & 59.5 & $2007^{\mathrm{a}}$ & $50-65$ \\
\hline Italy $^{\mathrm{d}}$ & 52 & 57 & 52 & 57 & 54 & 58 & 57 & 60 & 57 & 60 & $2007^{\mathrm{a}}$ & $50-69$ \\
\hline Poland & & & & & & & & & 55 & 60 & $2007^{\mathrm{a}}$ & $50-69$ \\
\hline Austria & 55 & 60 & 55 & 60 & 55 & 60 & 56.5 & 60 & 57 & 60 & $2008^{a}$ & $40-69$ \\
\hline Ireland & 65 & 65 & 65 & 65 & 65 & 65 & 65 & 65 & 65 & 65 & 2008 & $50-64$ \\
\hline Slovenia & & & & & & & & & 58 & 61 & 2008 & $50-69$ \\
\hline Germany & 60 & 65 & 60 & 65 & 60 & 65 & 60 & 65 & 60 & 65 & $2009^{a}$ & $50-69$ \\
\hline Latvia & & & & & & & & & 59 & 61 & 2009 & $50-69$ \\
\hline Malta & & & & & & & & & 60 & 60 & 2009 & $50-59$ \\
\hline Spain & 61 & 65 & 61 & 65 & 61 & 65 & 61 & 65 & 61 & 65 & 2009 & $50-69$ \\
\hline Denmark & 60 & 67 & 60 & 67 & 60 & 67 & 60 & 67 & 60 & 65 & 2010 & $50-69$ \\
\hline Greece & 55 & 60 & 55 & 60 & 55 & 60 & 55 & 60 & 55 & 60 & None & - \\
\hline Slovakia & & & & & & & & & 62 & 62 & None & - \\
\hline
\end{tabular}




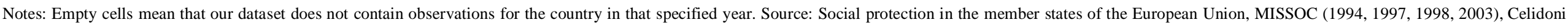
and Rebba (2017), Euwals et al.(2010), Jousten et al.(2010), Mazzonna and Peracchi (2014) and Staubli and Zweimuller (2013) for the retirement ages and Altobelli and Lattanzi (2014) for the program characteristics.

${ }^{a}$ indicates that regional program existed before it reached nationwide coverage.

${ }^{\mathrm{b}}$ In the dataset we distinguish between Great Britain and Northern Ireland. In Northern Ireland, the age range of the program was 50-64 until 2003, and 50-70 from 2004 onwards.

${ }^{c}$ The age range was 50-70 in 1997, and 50-74 from 1998 onwards. ERA and ORA are respectively the early retirement age and official retirement age.

${ }^{\mathrm{d}}$ The ERA for Italy refers to the eligibility age for the so-called "seniority pension", which is only available for individuals who have worked for at least 35 years. 
Table A.2: Summary statistics

\begin{tabular}{|c|c|c|c|c|c|c|c|c|}
\hline Variable & Mean & SD & Min & Max & $\mathbf{N}$ & $\begin{array}{l}\text { Mean } \\
\text { retired }\end{array}$ & \multicolumn{2}{|c|}{ Mean working } \\
\hline \multicolumn{9}{|c|}{ Preventive care use } \\
\hline Mammography in the past 12 months & 0.351 & 0.477 & 0 & 1 & 21,042 & 0.335 & 0.401 & $* * *$ \\
\hline $\begin{array}{l}\text { Manual breast examination in the past } 12 \\
\text { months }\end{array}$ & 0.387 & 0.487 & 0 & 1 & 21,031 & 0.359 & 0.457 & $* * *$ \\
\hline Ovary examination in the past 12 months & 0.222 & 0.416 & 0 & 1 & 20,960 & 0.188 & 0.286 & $* * *$ \\
\hline Pap smear test in the past 12 months & 0.332 & 0.471 & 0 & 1 & 21,011 & 0.275 & 0.435 & $* * *$ \\
\hline Osteoporosis test in the past 12 months & 0.158 & 0.365 & 0 & 1 & 20,933 & 0.179 & 0.131 & $* * *$ \\
\hline $\begin{array}{l}\text { Any other gynecological examination in the } \\
\text { past } 12 \text { months }\end{array}$ & 0.311 & 0.463 & 0 & 1 & 21,035 & 0.266 & 0.392 & $* * *$ \\
\hline \multicolumn{9}{|c|}{$\begin{array}{c}\text { Perceptions of early detection, prevention and treatment of breast cancer (1997 } \\
\text { and } 1998 \text { only) }\end{array}$} \\
\hline $\begin{array}{l}\text { Agreed: The sooner a cancer is detected, the } \\
\text { better it can be treated. }\end{array}$ & 0.979 & 0.143 & 0 & 1 & 5,347 & 0.978 & 0.980 & \\
\hline $\begin{array}{l}\text { Agreed: A mammography will detect signs } \\
\text { of breast cancer. }\end{array}$ & 0.964 & 0.187 & 0 & 1 & 5,217 & 0.967 & 0.959 & \\
\hline $\begin{array}{l}\text { Agreed: There are effective treatments for } \\
\text { breast cancer. }\end{array}$ & 0.896 & 0.305 & 0 & 1 & 4,744 & 0.894 & 0.898 & \\
\hline $\begin{array}{l}\text { Agreed: In most cases, you can be cured of } \\
\text { breast cancer if it is detected early enough. }\end{array}$ & 0.937 & 0.242 & 0 & 1 & 5,030 & 0.935 & 0.940 & \\
\hline $\begin{array}{l}\text { Agreed: Removal of the breast is the only } \\
\text { way to be cured of breast cancer. }\end{array}$ & 0.232 & 0.422 & 0 & 1 & 4,626 & 0.266 & 0.190 & $* * *$ \\
\hline $\begin{array}{l}\text { Agreed: Do you personally think that cancer } \\
\text { cannot be prevented? }\end{array}$ & 0.405 & 0.491 & 0 & 1 & 5,108 & 0.429 & 0.376 & $* * *$ \\
\hline Organized screening program & 0.345 & 0.475 & 0 & 1 & 21,156 & 0.352 & 0.389 & $* * *$ \\
\hline Retired & 0.560 & 0.496 & 0 & 1 & 18,042 & 1 & 0 & \\
\hline Age & 58.739 & 8.778 & 45 & 75 & 21,156 & 62.974 & 52.597 & $* * *$ \\
\hline \multicolumn{9}{|l|}{ Survey year } \\
\hline Year 1996 & & & & & 3,559 & & & \\
\hline Year 1997 & & & & & 3,406 & & & \\
\hline Year 1998 & & & & & 3,395 & & & \\
\hline Year 2003 & & & & & 3,726 & & & \\
\hline Year 2006 & & & & & 7,070 & & & \\
\hline \multicolumn{9}{|c|}{ Age when finished full-time education } \\
\hline 15 or younger & 0.426 & 0.495 & 0 & 1 & 21,061 & 0.475 & 0.259 & $* * *$ \\
\hline $16-19$ & 0.363 & 0.481 & 0 & 1 & 21,061 & 0.354 & 0.417 & $* * *$ \\
\hline 20 and above & 0.208 & 0.406 & 0 & 1 & 21,061 & 0.171 & 0.318 & $* * *$ \\
\hline Still studying & 0.003 & 0.053 & 0 & 1 & 21,061 & 0.000 & 0.006 & $* * *$ \\
\hline
\end{tabular}

Sources: EB66.2, EB59.0, EB49, EB47.2, EB44.3. Notes: The last column shows the significance of a t-test for equality of means between working and non-working women. *** $\mathrm{p}<0.01, * * \mathrm{p}<0.05, * \mathrm{p}<0.1$. 

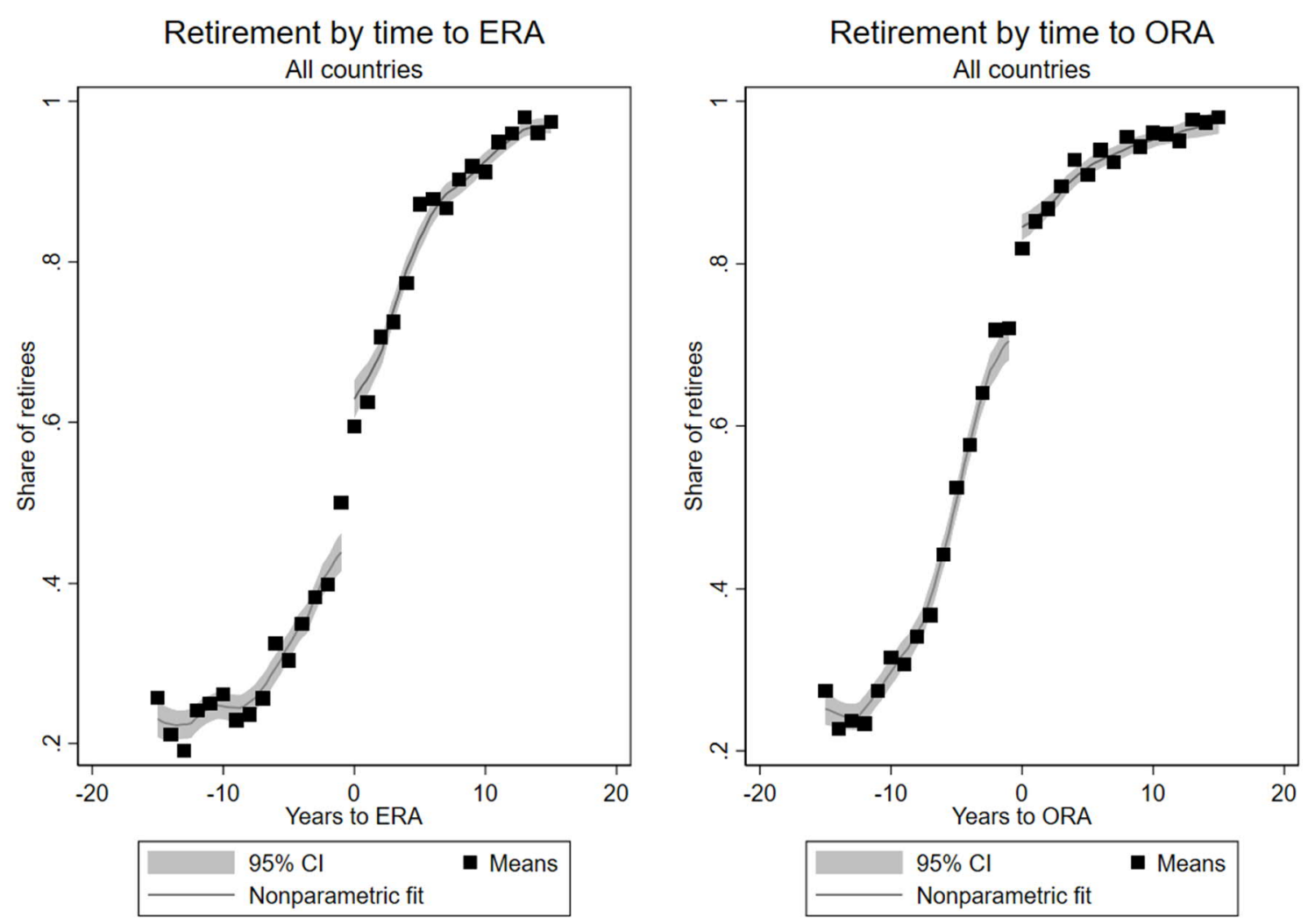

Fig. A.2 Share of retirees by time to state pension age. Source: Eurobarometer, own calculation. "Years to ERA" and "Years to ORA" are calculated by subtracting age from the relevant ERA or ORA. The markers show average retirement rates against year to ERA/ORA. The lines show local polynomial fits on both sides of the threshold, and the gray areas show 95 percent confidence intervals around the fit. 

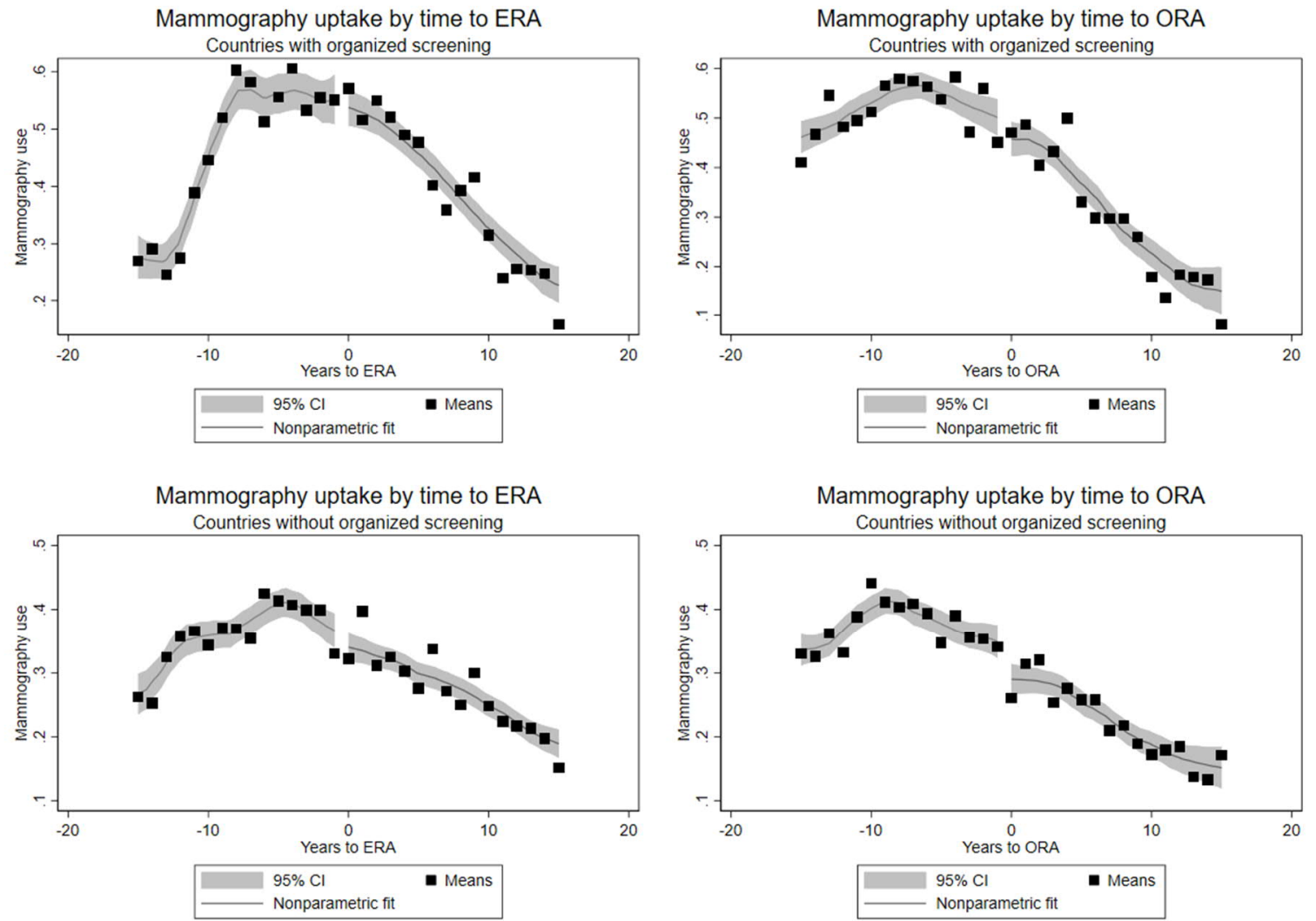

Fig. A.3 Mammography uptake by time to state pension age. Source: Eurobarometer, own calculation. "Years to ERA" and "Years to ORA" are calculated by subtracting age from the relevant ERA or ORA. The markers show average mammography use rates against year to ERA/ORA. The lines show local polynomial fits on both sides of the threshold, and the gray areas show 95 percent confidence intervals around the fit. 


\section{Above ERA}

Above ORA

\section{$0.194 * * *$}

(0.028)

$0.115 * * *$

(0.031)

35.6944

17,875

$$
\begin{gathered}
0.201 * * * \\
(0.033) \\
0.092 * * *
\end{gathered}
$$

(0.032)

17.8341

17,875

Sources: Eurobarometer, own calculations. All models include a country-specific quadratic age trend, education and country-by-year fixed effects. The interacted model includes a control variable for program existence and age range of the program. The sample includes women aged 45-75. Standard errors shown in parentheses are two-way clustered on countryyear and age. $* * * \mathrm{p}<0.01 ; * * \mathrm{p}<0.05 ; * \mathrm{p}<0.1$.

Table A.4: Regression results by program

Dependent variable: Mammography use in the past 12 months

Screening program throughout the study period
No screening program in study period
Retired
$-0.164$
$-0.233 * * *$
$(0.141)$
$(0.069)$
Wald F
7.8844
28.7513
$\mathrm{N}$
4,585
9,622

\begin{abstract}
Sources: Eurobarometer, own calculations. All models include a country-specific quadratic age trend, education and country-by-year fixed effects. The interacted model includes a control variable for program existence and age range of the program. The sample includes women aged 45-75. Standard errors shown in parentheses are two-way clustered on countryyear and age. $* * * \mathrm{p}<0.01 ; * \mathrm{p}<0.05 ; * \mathrm{p}<0.1$.
\end{abstract}




\begin{tabular}{|c|c|c|}
\hline \multicolumn{3}{|c|}{ A. Countries without pension reforms } \\
\hline Retired & $-0.209 * * *$ & $-0.253 * * *$ \\
\hline & $(0.080)$ & $(0.074)$ \\
\hline \multirow{2}{*}{\multicolumn{2}{|c|}{ Retired x program }} & $0.168 * *$ \\
\hline & & $(0.082)$ \\
\hline Wald F & 17.3906 & 6.42365 \\
\hline $\mathrm{N}$ & 9,887 & 9,887 \\
\hline \multicolumn{3}{|c|}{ B. Countries with pension reforms } \\
\hline \multirow[t]{2}{*}{ Retired } & $-0.290 * * *$ & $-0.340 * * *$ \\
\hline & $(0.101)$ & $(0.121)$ \\
\hline \multirow{2}{*}{\multicolumn{2}{|c|}{ Retired x program }} & 0.041 \\
\hline & & $(0.072)$ \\
\hline Wald F & 34.2458 & 16.2351 \\
\hline $\mathrm{N}$ & 7,988 & 7,988 \\
\hline
\end{tabular}

Sources: Eurobarometer, own calculations. All models include a country-specific quadratic age trend, education and country-by-year fixed effects. The interacted model includes a control variable for program existence and age range of the program. The sample includes women aged 45-75. Standard errors shown in parentheses are two-way clustered on countryyear and age. $* * * \mathrm{p}<0.01 ; * * \mathrm{p}<0.05 ; * \mathrm{p}<0.1$. 
Good health $(2 / 5$

SAH)
Mammography use in the past 12 months
Mammography use in the past 12 months

\begin{tabular}{lccc}
\hline Retired & $0.177 * *$ & $-0.232 * * *$ & $-0.221 * *$ \\
& $(0.083)$ & $(0.086)$ & $(0.086)$ \\
Good health & $(\mathbf{2 / 5}$ SAH) & & $-0.057 * *$ \\
& & & $(0.014)$ \\
Wald F & 23.768 & 23.833 & 25.113 \\
$\mathrm{~N}$ & 10585 & 10498 & 10498 \\
\hline \multicolumn{3}{r}{} \\
\hline
\end{tabular}

HH income above median
Mammography use in the past 12 months
Mammography use in the past 12 months

\begin{tabular}{lccc}
\hline Retired & -0.079 & $-0.281^{* * *}$ & $-0.279 * * *$ \\
& $(0.059)$ & $(0.097)$ & $(0.097)$ \\
\multicolumn{2}{l}{ HH income above median } & & 0.016 \\
& & & $(0.011)$ \\
Wald F & 30.171 & 29.737 & 29.934 \\
$\mathrm{~N}$ & 8777 & 8736 & 8736 \\
\hline \hline
\end{tabular}

Sources: Eurobarometer, own calculations. All models include controls for education, country-, year- and country-by-year fixed effects as well as a country-specific quadratic age trend. All models are based on a bandwidth of 15 years. "Good health" is a binary indicator for the top two categories of self-assessed health status, and "HH income above median" is a binary indicator for respondents with a household income above the median in their country of residence. Standard errors are clustered by country-year and age. $* * * p<0.001 ; * * p<0.01$; $* \mathrm{p}<0.05 ; \dagger \mathrm{p}<0.1$. 


\section{B. Specification curve analysis and placebo regressions}

The estimates from our preferred IV specification might be sensitive to several analytical choices, including the specification of the age trend, the sample selection or the definition of retirement. We assess the robustness of our results using a novel approach suggested by Simonsohn et al. (2015) (see also Christensen and Miguel (2018) for an overview and Rohrer et al. (2017) for an application in psychology). They propose that researchers define an extensive set of a priori plausible specifications, which are then estimated and visualized in a so-called "specification curve". For this paper, we focus on 36 different specifications, defined through a combination of age trend, age range, retirement definition and exclusion of observations within 12 months of the state pension age. The resulting specification curves allow us to assess the robustness of the results and identify the specification characteristics that affect our conclusions. ${ }^{21}$ Moreover, it is possible to test the joint significance of the curve with a permutation test. For this test, we generate 500 datasets that are consistent with the null hypothesis of no effect of retirement on mammography use. This is done by jointly permuting the assignment of the retirement variable as well as the instrument. ${ }^{22}$ Then, we estimate a specification curve on each of these generated datasets. The chosen test statistic for this analysis is the number of specifications that showed the same sign as the estimate from our preferred specification and are significant at the 5 percent level. We compare the value for the observed specification curve against the 500 values obtained from the generated specification curves to derive an exact p-value. This p-value can be interpreted as the probability that the statistic is at least as extreme as the observed value if the null hypothesis holds.

The specification curves display all specifications resulting from the combination of the following characteristics: the degree of the polynomial, a country-specific age trend, restricting the sample to women within the age range of their country's screening program ${ }^{23}$, retirement definition (excluding homemakers, or including unemployed women) and omitting observations within the first 12 months after passing the ERA/ORA to address potential measurement error stemming from retrospective measurement of secondary preventive care use.

\footnotetext{
${ }^{21}$ Specification curve analysis cannot be used to select a preferred specification. Instead, it complements model selection procedures by visualizing differences across specifications.

22 We permute treatment and instrument assignment as a block to preserve the relationship between instrument and treatment. If we were to permute only one of these variables, the instrument would no longer affect the treatment status and our empirical model would not be valid.

${ }^{23}$ For the two countries that have to this date not introduced a screening program, we included observations within the most common age range, i.e., between 50 and 69 years old.
} 
Fig. B.1 shows the specification curve for the main The majority of specifications are negative and significant. There is not one specific characteristic that leads to find a nonsignificant result. However, it seems that the combination of a small age range (i.e., women within the age range of their country's screening program) and a country-specific age trend leads to an insignificant result. Even though ERA and ORA are within the age range of the screening program for all countries in our sample, in some cases the state pension ages are relatively close to the boundaries of the screening program's age range, which might affect the fit of a country-specific age trend.

The permutation test suggests that the specification curve is significantly different from randomly generated curves at the 1 percent level $(\mathrm{p}<0.002){ }^{24}$ Thus, we conclude that our results are fairly robust to changes in specification.
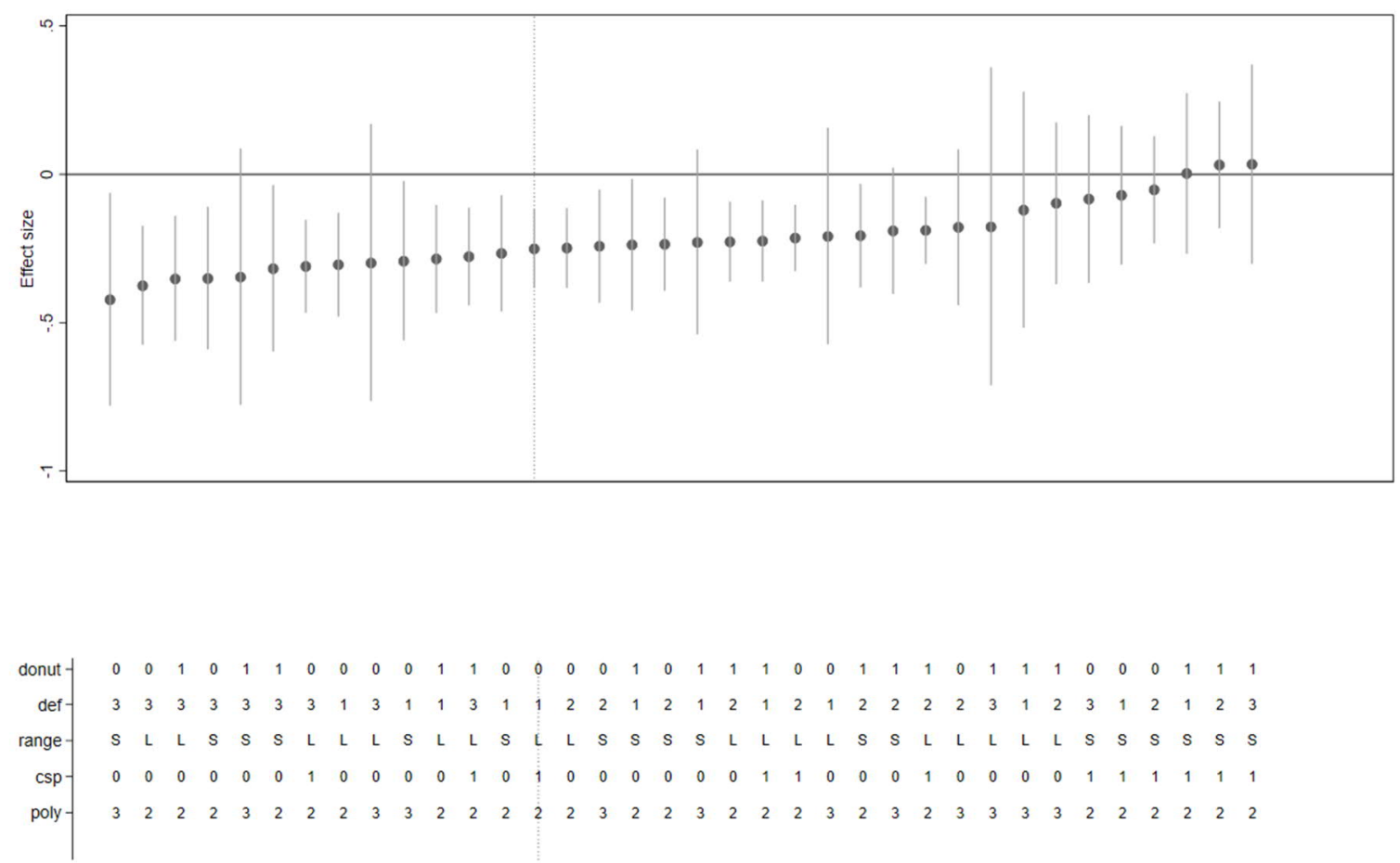

Fig. B.1 Specification curve for the basic model. Source: Eurobarometer, own calculations. The markers show the point estimates and the lines show 95 percent confidence intervals for the effect of retirement on mammography use in the past 12 months. The dotted line shows the preferred specification from Table 2. The lower panel shows the model specification. "poly" gives the degree of the polynomial, "csp" indicates whether the age trend is country-specific. "Range" indicates the age range, with "L" standing for ages $45-75$, and " $S$ " indicating the age range of the country's screening program (Table A.1). "Def" gives the definition of retirement status, definition 1 includes homemakers

${ }^{24}$ For the simulated specification curves, the number of negative and significant point estimates ranged from 0 to 13 (out of 36 specifications), while in our observed specification curve 21 estimates are negative and significant at the $5 \%$ level. 
as retired but excludes unemployed women. For definition 2 homemakers are coded as non-retired, and in definition 3 both homemakers and unemployed women are coded as retired. "Donut" indicates whether the first 12 months after the ERA and ORA were excluded or not. All models include further controls for education, and country-by-year fixed effects. Standard errors are clustered by country-year and age.
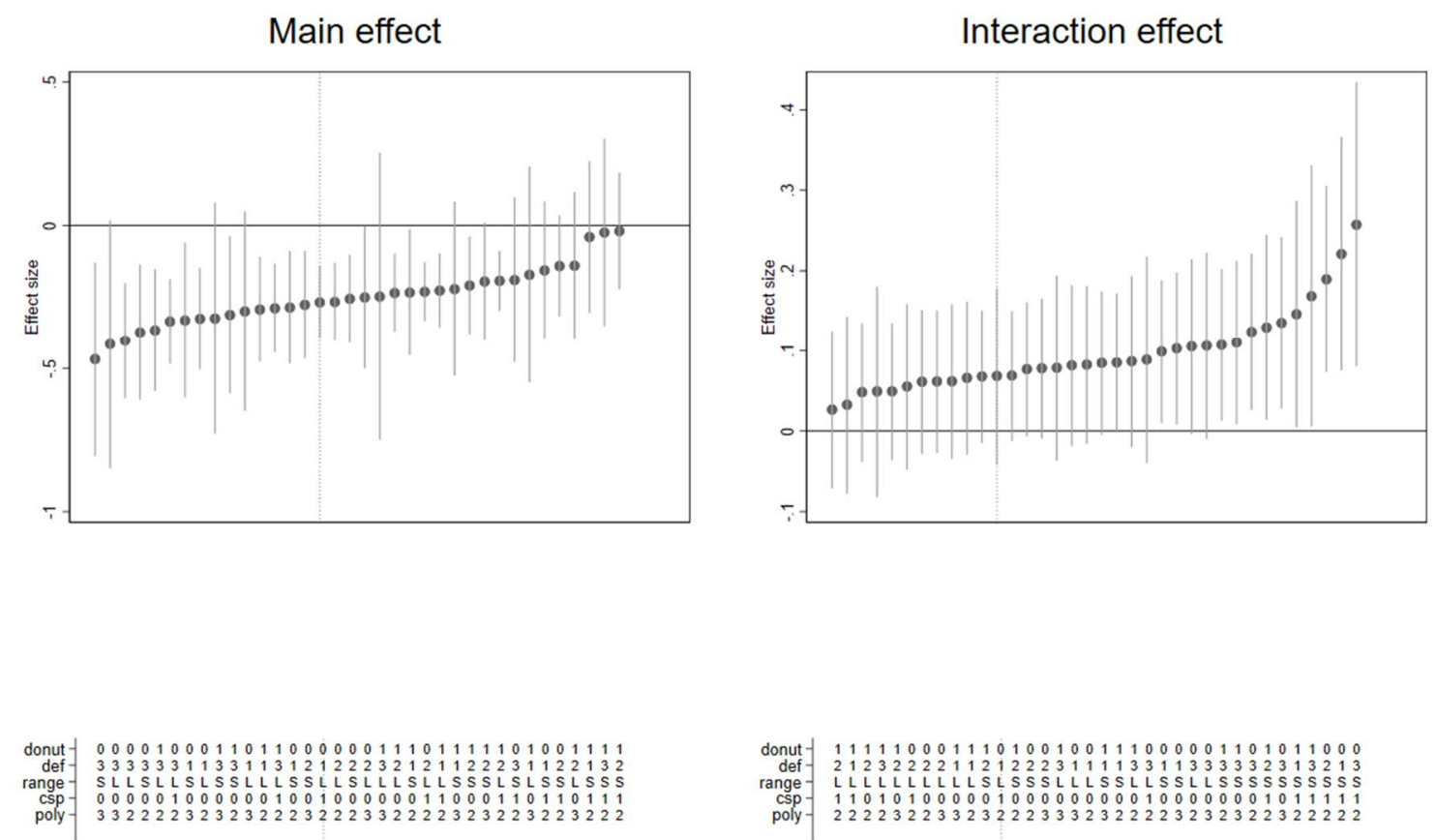

Fig. B.2 Specification curve for the interacted model. Source: Eurobarometer, own calculations. Panel a shows the main effect of retirement, and panel $b$ shows the interaction effect between retirement and screening program existence. The markers show the point estimates and the lines show 95 percent confidence intervals for the effect of retirement on mammography use in the past 12 months. The dotted line shows the preferred specification from Table 2. The lower panel shows the model specification. "poly" gives the degree of the polynomial, "csp" indicates whether the age trend is country-specific. "Range" indicates the age range, with "L" standing for ages 45-75, and "S" indicating the age range of the country's screening program (Table A.1). "Def" gives the definition of retirement status, definition 1 includes homemakers as retired but excludes unemployed women. For definition 2 homemakers are coded as non-retired, and in definition 3 both homemakers and unemployed women are coded as retired. "Donut" indicates whether the first 12 months after the ERA and ORA were excluded or not. All models include further controls for education, and country-by-year fixed effects. Standard errors are clustered by country-year and age.

Fig. B.2 shows specification curves for the main effect of retirement and the interaction effect between retirement and screening programs. Panel a shows that the main effect of retirement follows a very similar pattern to Figure B.1. For the interaction effect two thirds of the specifications provide non-significant point estimate, including our preferred specification. 
For the remaining specifications, the interaction effect between retirement and program existence is positive and significant although of a rather small magnitude.

Adding the two coefficients up provides the estimated effect of retirement for countries with a screening program. The specification curve of this combined effect is available in Figure B.3 and shows that retirement still has a strong negative impact on mammography use even if an organized screening program exists.
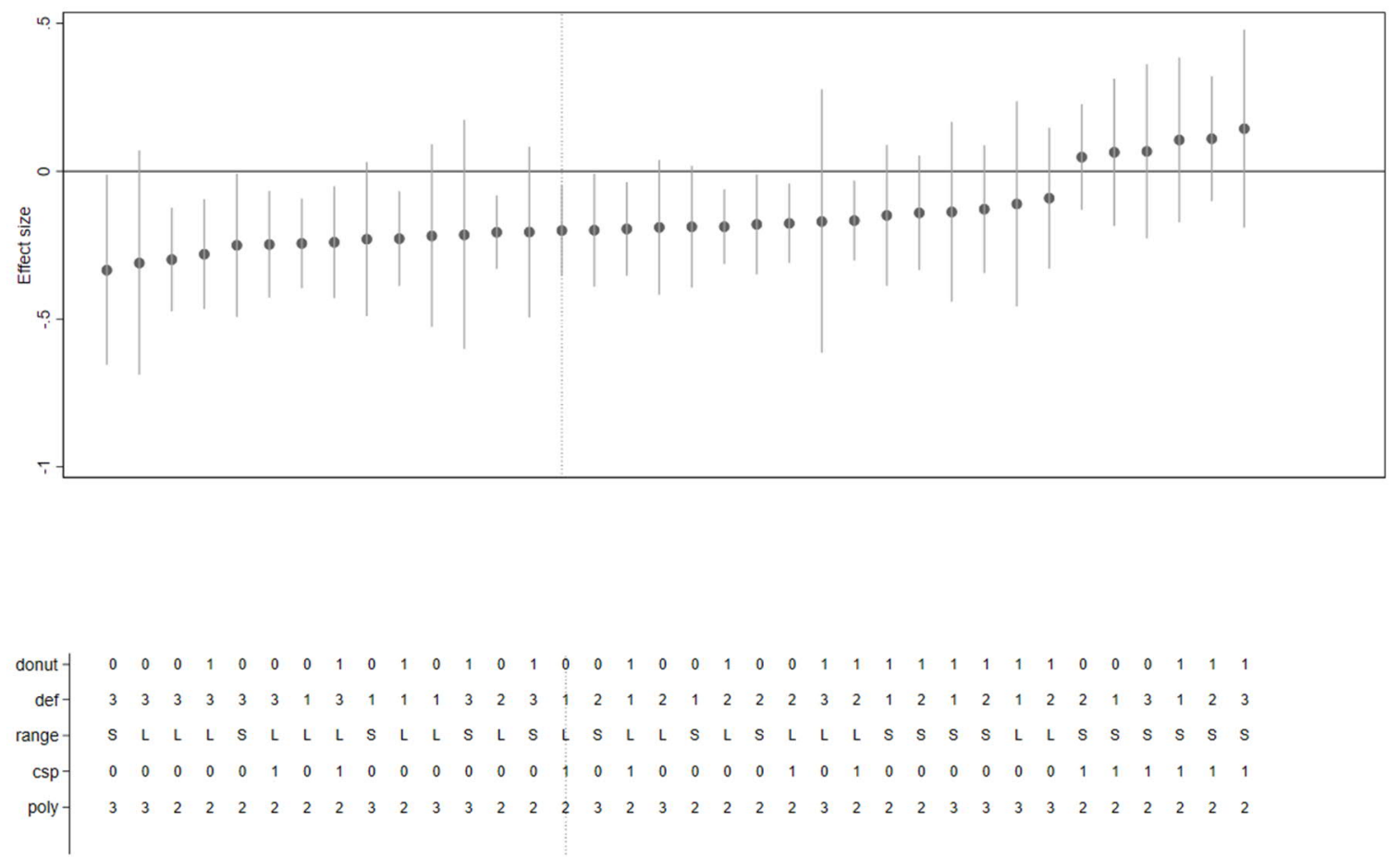

Fig. B.3 Specification curve for the combined effect in the interacted model. Source: Eurobarometer, own calculations. The markers show the point estimates and the lines show 95 percent confidence intervals for the effect of retirement on mammography use in the past 12 months for countries with an organized screening program. The dotted line shows the preferred specification from Table 2. The lower panel shows the model specification. "poly" gives the degree of the polynomial, "csp" indicates whether the age trend is country-specific. "Range" indicates the age range, with "L" standing for ages 45-75, and " $\mathrm{S}$ " indicating the age range of the country's screening program (Table A.1). "Def" gives the definition of retirement status, definition 1 includes homemakers as retired but excludes unemployed women. For definition 2 homemakers are coded as non-retired, and in definition 3 both homemakers and unemployed women are coded as retired. "Donut" indicates whether the first 12 month after the ERA and ORA were excluded or not. All models include further controls for education, and country-by-year fixed effects. Standard errors are clustered by country-year and age. 
The permutation test suggests that the specification curves for both the effect of retirement and the interaction term are significant at the 1 percent level $(p<0.002$ for the effect of retirement, $\mathrm{p}<0.006$ for the interaction effect). We can also conduct a joint test by using the number of specifications with a negative and significant effect of retirement and a positive and significant interaction term as our test statistic. In this case, the observed specification curves are jointly significant at the 5 percent level $(\mathrm{p}<0.004) .{ }^{25}$ Therefore, we conclude that the effect of retirement on mammography use is negative overall, but it might be mitigated to a small extent by the existence of organized screening programs.

Table B.1 reports the estimated coefficients for robustness checks, in which we only change one aspect at a time. With one exception, these robustness checks are all included in the specification curves. The exception is that we drop one country at a time to check whether our effect was driven by a specific country. Overall, these robustness checks confirm our conclusion. We find negative and significant effects of retirement on mammography use in all models, with the exception of a model where we restrict the sample to women within the age range of their country's screening program. However, as noted above this result seems to be caused by a particular combination of age range and country-specific age trend. In unreported regressions, we also estimate our model for each country individually. While the sample sizes are too small to draw robust conclusions for individual countries, we note that the point estimate is negative for 16 out of 25 countries.

\footnotetext{
${ }^{25}$ For the observed specification curve, 5 out of 36 models provide a negative and significant estimate for the effect of retirement and a positive and significant estimate for the interaction term. Among the simulated curves, the number of specifications with such results ranges from 0 to 6 .
} 
Table B.1: Robustness checks

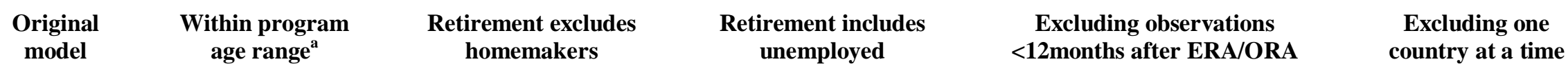

\begin{tabular}{|c|c|c|c|c|c|c|}
\hline \multicolumn{7}{|c|}{ A. Full sample } \\
\hline \multirow[t]{2}{*}{ Retired } & $-0.251 * * *$ & -0.043 & $-0.214 * * *$ & $-0.309 * * *$ & $-0.224 * * *$ & {$[-0.217,-0.296]^{b}$} \\
\hline & $(0.067)$ & $(0.117)$ & $(0.057)$ & $(0.080)$ & $(0.070)$ & - \\
\hline Wald F & 35.694 & 19.403 & 53.21 & 25.537 & 33.857 & - \\
\hline $\mathrm{N}$ & 17,875 & 13,285 & 17,875 & 17,875 & 16,851 & - \\
\hline \multicolumn{7}{|c|}{ B. Interacted model } \\
\hline \multirow[t]{2}{*}{ Retired } & $-0.268 * * *$ & -0.134 & $-0.228 * * *$ & $-0.337 * * *$ & $-0.227 * * *$ & {$[-0.234,-0.328]^{\mathrm{b}}$} \\
\hline & $(0.065)$ & $(0.126)$ & $(0.053)$ & $(0.076)$ & $(0.066)$ & - \\
\hline \multirow[t]{2}{*}{ Retired x program } & 0.068 & $0.221 * * *$ & 0.061 & 0.077 & 0.033 & {$[0.035,0.104]^{\mathrm{c}}$} \\
\hline & $(0.056)$ & $(0.077)$ & $(0.059)$ & $(0.057)$ & $(0.056)$ & - \\
\hline Wald F & 17.834 & 9.453 & 27.82 & 12.829 & 17.561 & - \\
\hline $\mathrm{N}$ & 17,875 & 13,285 & 17,875 & 17,875 & 16,851 & - \\
\hline
\end{tabular}

${ }^{a}$ The model includes only observations within the age range of the respective program. For countries without a mammography program, we only used observations between age 50 and age 69.

${ }^{\mathrm{b}}$ All estimates are significant at the $1 \%$ level.

${ }^{\mathrm{c}}$ One estimate is significant at the $10 \%$ level.

Sources: Eurobarometer, own calculations. All models include controls for education, country-by-year fixed effects as well as a country-specific quadratic age trend. All models except the one in column 3 include women aged 45 to 75 . All models in panel B include a control variable for program existence and age range of the program. Standard errors are clustered by countryyear and age. $* * * \mathrm{p}<0.01 ; * * \mathrm{p}<0.05 ; * \mathrm{p}<0.1$ 
Table B.2: Placebo outcomes

\begin{tabular}{cccc}
$\begin{array}{c}\text { Finished } \\
\text { education } \\
\text { before age }\end{array}$ & $\begin{array}{c}\text { Finished } \\
\text { education } \\
\text { between ages }\end{array}$ & $\begin{array}{c}\text { Finished } \\
\text { education } \\
\text { after age 19 }\end{array}$ & $\begin{array}{c}\text { Mammography } \\
\text { use placebo state } \\
\text { pension ages }\end{array}$ \\
\hline 16 & 16 and 19 & & .
\end{tabular}

\begin{tabular}{lcccc}
\hline \multicolumn{5}{c}{ A. Full sample } \\
\hline Retired & 0.027 & 0.022 & -0.049 & -0.31 \\
& $(0.059)$ & $(0.046)$ & $(0.051)$ & $(0.367)$ \\
Wald F & & & \\
$\mathrm{N}$ & 36.405 & 36.405 & 36.405 & 1.684 \\
\hline & 17,917 & 17,917 & 17,917 & 17,875 \\
\hline Retired & 0.018 & B. Interacted model & \\
& $(0.057)$ & $(0.042)$ & -0.033 & -0.292 \\
Retired x program & 0.021 & 0.019 & -0.04 & $(0.384)$ \\
& $(0.048)$ & $(0.035)$ & $(0.037)$ & -0.1 \\
& & & & $(0.108)$ \\
Wald F & 18.082 & 18.082 & 18.082 & 1.164 \\
$\mathrm{~N}$ & 17,917 & 17,917 & 17,917 & 17,875 \\
\hline \hline
\end{tabular}

Sources: Eurobarometer, own calculations. All models include controls for education, country-, year- and country-by-year fixed effects as well as a country-specific quadratic age trend. The sample includes women aged 45 to 75 . Standard errors are clustered by countryyear and age. $* * * \mathrm{p}<0.01 ; * * \mathrm{p}<0.05 ; * \mathrm{p}<0.1$.

We conduct a placebo test and estimate our main specification with our three levels of education (finished full-time education before age 16, between ages 16 and 19, after age 19) as outcome variables. Since education is a pre-determined variable, it should not be affected by retirement. Furthermore, we test the effect of placebo state pension ages. The results are shown in Table B.2. All estimated effects are close to zero and not statistically significant at conventional levels.

We conclude that the specification curves and the placebo analyses confirm the robustness of our findings. 


\section{References}

Altobelli, E., \& Lattanzi, A. (2014). Breast cancer in European Union: An update of screening programmes as of March 2014. International Journal of Oncology, 45(5), 1785-1792.

Celidoni, M., \& Rebba, V. (2017). Healthier lifestyles after retirement in Europe? Evidence from SHARE. The European Journal of Health Economics, 18(7), 805-830. https://doi.org/10.1007/s10198-016-0828-8

Christensen, G., \& Miguel, E. (2018). Transparency, Reproducibility, and the Credibility of Economics Research. Journal of Economic Literature, 56(3), 920-980. https://doi.org/10.1257/jel.20171350

Euwals, R., van Vuuren, D., \& Wolthoff, R. (2010). Early Retirement Behaviour in the Netherlands: Evidence From a Policy Reform. De Economist, 158(3), 209-236. https://doi.org/10.1007/s10645-010-9139-0

Jousten, A., Lefèbvre, M., Perelman, S., \& Pestieau, P. (2010). The Effects of Early Retirement on Youth Unemployment: The Case of Belgium. In Social Security Programs and Retirement around the World: The Relationship to Youth Employment (pp. 47-76). University of Chicago Press. http://www.nber.org/chapters/c8251

Mazzonna, F., \& Peracchi, F. (2014). Unhealthy retirement? Evidence of occupation heterogeneity. USI Università della Svizzera italiana. https://ideas.repec.org/p/lug/wpidep/1401.html

Rohrer, J. M., Egloff, B., \& Schmukle, S. C. (2017). Probing Birth-Order Effects on Narrow Traits Using Specification-Curve Analysis. Psychological Science, 28(12), 18211832. https://doi.org/10.1177/0956797617723726

Simonsohn, U., Simmons, J. P., \& Nelson, L. D. (2015). Specification Curve: Descriptive and Inferential Statistics on All Reasonable Specifications (SSRN Scholarly Paper ID 2694998). Social Science Research Network. https://papers.ssrn.com/abstract $=2694998$

Staubli, S., \& Zweimüller, J. (2013). Does raising the early retirement age increase employment of older workers? Journal of Public Economics, 108(Supplement C), 1732. https://doi.org/10.1016/j.jpubeco.2013.09.003 